Türk Dili Araştırmaları Yılığı-BELLETEN / Yearbook of Turkic Studies BELLETEN

Yıl/Year: 2018, Cilt/Volume: 66, Sayı/Issue: 1 - ISSN: 0564-5050/e-ISSN: 2651-5113 Ankara, TÜRKIYE/TURKEY DOI Numarası/DOI Number: 10.32925/tday.2018.2

\title{
TÜRKİYE TÜRKÇESİ AĞIZLARINDA YAPIM EKLERİ I: YAZI DILIINDE BULUNMAYAN YAPIM EKLERI'
}

\author{
Ferdi GÜZEL**
}

$\ddot{O}_{z e t}$

Türkiye Türkçesi ă̆ızları, yazı diline göre çok daha zengin bir yapım eki varlı̆̆ına sahiptir. Türkiye Türkçesi ă̆ızlarındaki yapım eklerinin sayısı yazı dilindeki yapım eklerinin iki katından fazladır. Ağızlardaki pek çok yapım eki, yazı diline göre daha işlektirve bu yapım eklerininyazı dilinde görülmeyen pekçokfarklı işlevi vardır. Türkiye Türkçesi ă̆ızlarındaki yapım eklerinden 140 kadarı yazı dilinde bulunmamaktadır. Tarihî lehçelerde mevcut olup da yazı dilinde unutulmuş olan pek çok yapım eki, Türkiye Türkçesi ă̆ızlarında varlı̆̆ını korumuştur, çağdaş lehçelerde kullanılan ama Türkiye Türkçesi yazı dilinde bulunmayan yapım eklerinin birçoğu da çă̆daş lehçelerdekine benzer işlevlerle Türkiye Türkçesi ağızlarında yer almaktadır. Bazı yapım ekleri ise tarihî ve çağdaş lehçelerde bulunmamakta, Türk dili coğrafyasında sadece Türkiye Türkçesi ă̆ızlarında görülmektedir. Türkiye Türkçesi ağızlarındaki bazı yapım ekleri ve bu eklerle kurulu birtakım kelimeler tarihî lehçelerde nadir görülen yapım eklerinin varlı̆̆ını doğrulamakta, Türk dili tarihinin pek çok sorununa ışık tutmakta ve bu sorunların çözümüne katkı sağlamaktadır.

Anahtar kelimeler: Türkiye Türkçesi ă̆ızları, söz yapımı, yapım ekleri.

\section{The Derivational Suffixes of the Dialects of Turkish I: The Derivational Suffixes Not Existing in Written Language}

\section{Abstract}

It is pointed out that the dialects of Turkish have more suffixes than the written language. Most of these suffixes are more practical and have many different functions that do not exist in the written language. In the written language aren 't approximately

* Bu çalışma, 2015 yılında Fırat Üniversitesi, Sosyal Bilimler Enstitüsü’nde savunulan "Türkiye Türkçesi Ağızlarında Söz Yapımı" adlı doktora tezinden üretilmiştir.

** Dr. Öğretim Üyesi, Bayburt Üniversitesi İnsan ve Toplum Bilimleri Fakültesi Türk Dili ve Edebiyatı Bölümü Yeni Türk Dili ABD, guzelferdi@hotmail.com, https://orcid.org/0000$\underline{0002-5601-5661}$ 
140 of suffixes in the dialects of Turkish. It is seen that most of the suffixes used in historical dialects but forgotten in written language keep their existence in the dialects of Turkish. It is also seen that most of the suffixes that do not exist in our written language but used in modern dialects are in the dialects of Turkish with similar functions. Some of them are only seen in the dialects of Turkish in Turkey It is concluded that the words and forms in the dialects of Turkish enlighten many problems in the Turkish Language history and contribute to their solutions.

Key words: dialects of Turkish in Turkey, word formation, derivational suffixes.

\section{Giriş}

Türkiye Türkçesi Ağızları (TTA), Türk dili tarihindeki pek çok soruna 1şık tutacak veriler ile doludur. Tarihî lehçelerdeki pek çok kelimenin ve yapım ekinin TTA'da korunduğu, çağdaş lehçelerde bulunan birçok kelime ve yapım ekinin de TTA'da aynen veya benzer biçimlerle yer aldığı görülmektedir.

Türk dili tarihi ile ilgili pek çok problemin çözümüne katkı sağlayacak bu hazineden yeterince yararlanıldığı söylenemez.

Türkçenin ağızlardaki türetim gücünü, türetim eklerinin zenginliğini göstermek amacıyla 96 kitap, 1 doçentlik tezi, 18 doktora tezi, 178 yüksek lisans tezi, 53 makale ve bildiri tarafımızdan incelenmiş, incelenen ağız sözlüklerinden, Derleme Sözlüğ̈̈’ne katkı sağlamak amacıyla yazılan makale ve bildirilerden, diğer ağız çalışmalarının sözlük ve şekil bilgisi bölümlerinden yaklaşık 40.000 kelime fişlenmiştir. Asıl amaç yazı dilinde bulunmayan türemiş kelimeleri toplamak, yazı dilinde bulunmayan yapım eklerini tespit etmek ve bu eklerin farklı işlevlerini belirlemek olduğu için yazı dilinde bulunup da ağızlarda aynen veya çeşitli ses olayları ile farklı şekillerde yer alan kelimeler incelemenin kapsamı dişında tutulmuştur.

Türemiş olabileceği düşünülen kelimelerin yapısının anlaşılabilmesi için etimolojik kaynaklar incelenmiş, Türkçedeki yabancı unsurlar hakkında yapılan çalışmalara, tarihî ve çağdaş lehçeler ile ilgili sözlüklere başvurulmuştur. Aynı kelimenin çeşitli ses olayları ile ortaya çıkmış şekilleri, asıl şekille birleştirilmiş ve yabancı olduklarına kesin kanaat getirilen kelimeler ile yapısı hakkında herhangi bir hükme varılamayan kelimeler çıkarılmıştır. Geriye kalan yaklaşık 25.000 türemiş kelimeye dayanan söz varlığı esas alınarak Türkiye Türkçesi ağızlarında görülen yapım ekleri detaylı bir şekilde incelenmiştir.

Bu çalışmada TTA'daki yapım eki varlığg ve bu eklerin işleklik derecesi hakkında genel bir bilgi verildikten sonra yazı dilinde bulunmayan 50 yapım eki üzerinde durulacak, bu eklerle türemiş kelimelerden bir kısmına yer verilecektir. Elbette ki burada yer alan unsurlardan bir kısmının yapım eki olup olmadığı tartışılabilir, bazı eklerin ve kelimelerin yapısı hakkında farklı görüşler 
ileri sürülebilir. Bu çalışma ile amaçlananlardan biri de TTA'daki yapım eki varlığını tartışmaya açmaktır.

\section{TTA'da Yapım Ekleri ve Türemiş Kelime Varlığı}

TTA'da 133 isimden isim, 96 fiilden isim, 34 isimden fiil, 61 fiilden fiil yapma eki olmak üzere toplam 324 yapım eki tespit edilmiştir. TTA'da yazı dilindeki kelimelerden farklı kelimeler türetmediği için buraya alınmayan $+\mathrm{Ar},+\mathrm{dIz}$ vb. ekler; birleşik bir ek olarak da ele alınabilecek -dIz, -nAz, -III, + CImAn vb. ekler; farklı kaynaklardan geldiği halde kesin olarak birbirinden ayırt edilemediği için aynı başlıkta ele alınan ekler ile yapım eki olup olmadığı kesin belli olmayan bazı unsurlar ${ }^{1}$ da göz önünde bulundurulursa bu sayı çok artacaktır. TTA'nın zengin bir yapım eki varlığına sahip olduğu görülmektedir. ${ }^{2}$

TTA'da isimden isim yapma ekleri ile türetilmiş 10456, fiilden isim yapma ekleri ile türetilmiş 7640, isimden fiil yapma ekleri ile türetilmiş 4440, fiilden fiil yapma ekleri ile türetilmiş 2417 , toplamda yazı dilinde olmayan $24953^{3}$ türemiş kelime tespit edilmiştir. ${ }^{4}$ Sadece inceleyebildiğimiz eserlerdeki yazı dilinde bulunmayan türemiş kelimeleri gösteren bu sayı, TTA'nın ne kadar büyük bir hazine olduğunu açık bir şekilde ortaya koymaktadır.

Bu çalışmada yer alan kelimelerin büyük bir kısmı kalıcı kelimelerdir. Kalıcı kelime türetmeyen yapım eklerinin varyantlarını ve farklı işlevlerini göstermek amacıyla fişlenen kelimeler dışında kalıcı olmayan kelimeler değerlendirmeye tabi tutulmamıştır. +gil, +eli, +o vb. ekler TTA'da yaygın kullanıma sahip eklerdir. Bu tür eklerle ilgili fişlenen malzemeden, farklı şekilleri ve farklı işlevleri göstermeye yetecek kadarı kullanılmış, eklerin işleklik ora-

1 Bu unsurlardan bir kısmı şunlardır: +du: $s a v d u$ "sağ, salim, selamet" (STİA, s. 260); +sat: gitsat "kıtça, az, azıcık" (UİA, s. 379); -çıl: sıkçıl "cimri" (DS, s. 3605); -let: sılhlet "kalabalık yer" (HrpA, s. 158), siklet "sıkıntı" (KsYA, s. 1153); \pm p: uslup “akıllı” (DS, s. 4043), örülüp "omuzdan aşağıya sarkıtılan saç örgüleri” (DS, s. 3353), tölüp "kural, düzen, yol, usul” (DS, s. 3980); +irle- (<+arla-): beşirle- "başarmak, becermek" (DS, s. 644)...

2 Banguoğlu'nda (2004, s. 158-294) 152, Ergin'de (1990, s. 145-205) 127, Korkmaz'da (2003, s. 31-137) 163 yapım eki yer almaktadır (Korkmaz, fiilden isim yapan ekler bölümünde zarf-fiil eklerine de yer verdiği için yapım eki sayısı diğer çalışmalara göre daha fazla görünmektedir).

3 Temelde 'sözlük okuma' gibi büyük bir dikkat ve sabır isteyen bir uğraşa dayanan bu çalışmada okuma, fişleme ve tasnif aşamalarında bazı kelimelerin gözden kaçması ve yanlış değerlendirildiği için çalışmaya dâhil edilmemiş bazı verilerin olması kaçınılmazdır. Bazı kelimeler de yanlış çözümlendiği için olması gereken yerden farklı bir bölümde yer alabilir.

4 Eklerin yazı dilindeki türetim gücü ile karşılaştırmak için bk. (Özel, 1977, s. 21-22; Uzun vd., 1992, s. 117-122). (Özel'in çalışmasında Türkçe Sözlük'ün 5. baskısı kullanılmış, yaklaşık 13.500 türemiş kelime tespit edilmiştir; Uzun ve arkadaşlarının çalışmasında Türkçe Sözlük'ün 7. baskısı kullanılmış, 14.635 türemiş kelime tespit edilmiştir). 
nını gösteren tablolara da fişlenen malzemenin tamamı değil, ilgili ekte kaç kelime örnek verilmişse o sayı yazılmıştır.

TTA'da tespit ettiğimiz yapım ekleri ve bu eklerle türetilen kelimelerin sayısı aşağıdaki tablolarda gösterilmiştir:

Tablo 1: İsimden İsim Yapma Ekleri

\begin{tabular}{|c|c|c|c|c|c|}
\hline Yapım Eki & $\begin{array}{c}\text { Türemiş } \\
\text { Kelime } \\
\text { Sayıs }\end{array}$ & Yapım Eki & $\begin{array}{c}\text { Türemis } \\
\text { Kelime } \\
\text { Sayıs }\end{array}$ & Yapım Eki & $\begin{array}{c}\text { Türemiş } \\
\text { Kelime } \\
\text { Sayıs }\end{array}$ \\
\hline$+A$ & 219 & $+d I k /+d U k$ & 17 & $+m$ AldAk & 5 \\
\hline$+A c ̧$ & 30 & $+d I m /+d U m$ & 15 & $+m A n$ & 110 \\
\hline$+A d A k$ & 68 & $+D I r /+D U r$ & 28 & $+m A r$ & 6 \\
\hline$+A d A n$ & 24 & $+D I r I k /+D U r U k$ & 62 & $+m A t$ & 7 \\
\hline$+A d A n A k$ & 10 & $+d \operatorname{IrIm} /+d U r U m$ & 9 & $+m c a k$ & 2 \\
\hline$+A \breve{g} I$ & 36 & $\begin{array}{l}+ \text { DIrmA / + DUr- } \\
m A\end{array}$ & 4 & $+m c ̧ ı l$ & 1 \\
\hline$+A k$ & 223 & + ĕgin $(<+$ egün $)$ & 4 & $+m I k /+m U k$ & 27 \\
\hline$+A l$ & 48 & $+e l i$ & 7 & $+m I r /+m U r$ & 12 \\
\hline$+A l A k$ & 101 & $+G A$ & 51 & $+(I) m s A k$ & 6 \\
\hline$+A m$ & 7 & $+G A c ̧$ & 19 & $+m s A v I$ & 3 \\
\hline$+A m A c$ & 5 & $+G A n$ & 43 & $+(I) m s I /+(U) m s U$ & 6 \\
\hline$+A m A k$ & 5 & $+G I /+G U$ & 52 & $+(I) m s U r A k$ & 4 \\
\hline$+A m I k /+A m U k$ & 42 & $+G I c ̧ /+G U c ̧$ & 17 & $+m s U k$ & 4 \\
\hline$+A m A n$ & 2 & $+g I l /+g U l$ & 13 & $+m t I$ & 3 \\
\hline$+A n$ & 111 & $+G I n /+G U n$ & 10 & $\begin{array}{l}+(I) m t I k /+(U) \\
m t U k\end{array}$ & 2 \\
\hline$+A n A k$ & 20 & $+g I r$ & 7 & $\begin{array}{l}+(I) m t I r A k /+(U) \\
m t I r A k\end{array}$ & 2 \\
\hline$+A \eta I$ & 18 & + gil & 5 & $+(u) m t u l$ & 2 \\
\hline+ AntA & 7 & + gine & 41 & $+m U_{S ̧}$ & 6 \\
\hline$+A p A$ & 11 & $+I /+U$ & 166 & $+(I) n /+(U n)$ & 37 \\
\hline$+a r$ & 5 & $+I l /+U l$ & 117 & $+(I) n c I /+(U) n c U$ & 4 \\
\hline$+A t$ & 14 & $+I n /+U n$ & 39 & $+(I) n t I /+(U) n t U$ & 20 \\
\hline$+A y$ & 7 & $+I r /+U r$ & 93 & $+o$ & 20 \\
\hline$+A z$ & 62 & $+I_{\text {Ş }} /+U_{S ̧}$ & 11 & $+o s ̧$ & 8 \\
\hline$+b i c ̧$ & 3 & $+(I) k /+(U) k$ & 396 & $+(I) r /+(U) r$ & 25 \\
\hline$+C A$ & 372 & $+k A,+k o$ & 12 & $+r A k$ & 116 \\
\hline$+C A \breve{g} I z,+C I \breve{g} A z$ & 28 & $+k i$ & 9 & $+s A$ & 17 \\
\hline$+C A k$ & 293 & $+(I) l /+(U) l$ & 46 & $+s A v I(<+s A \breve{g} I)$ & 22 \\
\hline+ CAlIk & 72 & $+l A$ & 12 & $+s A k$ & 100 \\
\hline$+C A n$ & 47 & $+l A(<+l A-g)$ & 8 & $+s A l$ & 11 \\
\hline$+c A n A$ & 27 & $+l A c ̧$ & 19 & + sAlIk & 21 \\
\hline$+C I /+C U$ & 778 & $+l A \breve{g} I$ & 61 & $+s A n,+s A \eta$ & 9 \\
\hline$+C I k /+C U k$ & 509 & $+l A k$ & 340 & $\begin{array}{l}+s I /+s U(<+s I- \\
g)\end{array}$ & 66 \\
\hline
\end{tabular}




\begin{tabular}{|c|c|c|c|c|c|}
\hline$+C I l /+C U l$ & 96 & $+l A m A$ & 315 & $+s I k /+s U k$ & 32 \\
\hline+ cllah $/+$ culah & 5 & $+l A \eta$ & 75 & $+s I l /+s U l$ & 7 \\
\hline$+c I l A y I n$ & 3 & $+l A y I n$ & 56 & $+s I n /+s U n$ & 10 \\
\hline+ CIlIk / + CUlUk & 38 & $+l A z$ & 23 & $+s \operatorname{Ir} A k$ & 3 \\
\hline$+C I n /+C U n$ & 32 & $+l I /+l U$ & 1280 & $+s I z /+s U z$ & 325 \\
\hline$+(I) c ̧ /+(U) c ̧$ & 71 & $+l I c ̧ /+l U_{c}$ & 6 & $+(I)_{S ̧} /+(U)_{s ̧}$ & 46 \\
\hline$+d A c ̧$ & 4 & $+l I k /+l U k$ & 1757 & $+\operatorname{ş} \operatorname{In}$ & 2 \\
\hline$+D A k$ & 204 & $+(I) m /+(U) m$ & 34 & $+(I) t /+(U) t$ & 38 \\
\hline+ DAlIk & 3 & $+m A$ & 31 & $+t A$ & 14 \\
\hline$+d A m$ & 11 & $+m A c ̧$ & 22 & $+t I /+t U$ & 120 \\
\hline$+d A n$ & 20 & $+m A k$ & 79 & $+y$ & 8 \\
\hline$+D A s ̧$ & 38 & $+m A l$ & 3 & $+(I) z /+(U) z$ & 21 \\
\hline$+d I_{\zeta} /+d U_{c}$ & 3 & & \multicolumn{3}{|c|}{ Toplam Türemiş Kelime: 10456} \\
\hline
\end{tabular}

Tablo 2: Fiilden Isim Yapma Ekleri

\begin{tabular}{|c|c|c|c|c|c|}
\hline Yapım Eki & $\begin{array}{c}\text { Türemiş } \\
\text { Kelime } \\
\text { Sayıs }\end{array}$ & Yapım Eki & $\begin{array}{l}\text { Türemiş } \\
\text { Kelime } \\
\text { Sayıs }\end{array}$ & Yapım Eki & $\begin{array}{c}\text { Türemis } \\
\text { Kelime } \\
\text { Sayıs }\end{array}$ \\
\hline$-(y) A$ & 88 & $-c I$ & 6 & $-m A l$ & 11 \\
\hline$-(y) A c A k$ & 147 & $-c I k / c U k$ & 17 & $-m A n$ & 84 \\
\hline$-A c A n$ & 32 & $-c \operatorname{In}$ & 6 & $-m A n t A$ & 4 \\
\hline$-A c ̧$ & 102 & $-D A$ & 4 & $-m A n t I$ & 13 \\
\hline$-A \breve{g} A n$ & 81 & $-d A c ̧(<-D A c ̧ I)$ & 6 & $-m A r$ & 7 \\
\hline$-A \breve{g} I$ & 21 & $-D I /-D U$ & 169 & $-m A z$ & 74 \\
\hline$-A k$ & 550 & $-d I c ̧ / d U_{c}$ & 3 & $-m I k /-m U k$ & 118 \\
\hline$-A k l I$ & 6 & $-D I k /-D U k$ & 30 & $-m I l$ & 2 \\
\hline$-A l$ & 15 & -dIrIk / -dUrUk & 12 & $-m I r /-m U r$ & 9 \\
\hline -AlAç & 7 & $-G A$ & 96 & $-m I s ̧ /-m U s ̧$ & 51 \\
\hline -AlAk & 39 & $-G A c ̧$ & 188 & $-m I t /-m U t$ & 4 \\
\hline$-\operatorname{Alg} A$ & 42 & $-G A l$ & 35 & $-(I) m l I /-(U) m l U$ & 18 \\
\hline$-A m$ & 24 & $-G A n$ & 283 & $\begin{array}{l}-(I) m s A k /-(U) \\
m s A k\end{array}$ & 5 \\
\hline$-A m A$ & 25 & $-g A z$ & 12 & -(I)msIk / -(U)msUk & 5 \\
\hline$-A m A c ̧$ & 16 & $-G I /-G U$ & 324 & $\begin{array}{l}\text {-(I)msIrAk/-(U) } \\
m s U r A k\end{array}$ & 3 \\
\hline$-A m A k$ & 24 & $-G I c ̧ /-G U c ̧$ & 125 & -msur & 1 \\
\hline$-A m A n$ & 6 & $-G I l / G U l$ & 13 & $-(I) n /-(U) n$ & 70 \\
\hline$-A m A t$ & 8 & $-G I n /-G U n$ & 268 & $-n A l$ & 7 \\
\hline$-(y) A n$ & 495 & -GIntI /-GUntU & 9 & $-(I) n c ̧ /-(U) n c ̧$ & 44 \\
\hline$-A n A$ & 6 & $-G I r /-G U r$ & 10 & $-r,-A r,-(I) r /-(U) r$ & 160 \\
\hline$-A n A k$ & 73 & $-G I t /-G U t$ & 16 & $-s A k$ & 16 \\
\hline$-A r A k$ & 9 & $-I /-U$ & 217 & $-s A l$ & 9 \\
\hline$-A r c A$ & 25 & $-(y) I c I /-(y) U c U$ & 114 & $-s A n$ & 3 \\
\hline$-\operatorname{ArgI}$ & 5 & $-I_{\zeta \zeta} /-U_{c ̧}$ & 42 & $-s I /-s U$ & 5 \\
\hline
\end{tabular}




\begin{tabular}{|l|r|l|r|r|r|}
\hline$-A r I$ & 6 & $-(I) k /-(U) k$ & 933 & $-s I k /-s U k$ & 6 \\
\hline$-A s I$ & 26 & $-(I) l /-(U) l$ & 19 & $-s I l$ & 2 \\
\hline$-A t$ & 26 & $-l A m A$ & 2 & $-s I n$ & 2 \\
\hline$-A z$ & 27 & $-(I) m /-(U) m$ & 283 & $-(I) s /-(U) s ̧$ & 98 \\
\hline$-C A$ & 34 & $-m A$ & 632 & $-(I) t /-(U) t$ & 54 \\
\hline$-c A k$ & 78 & $-m A c A$ & 88 & $-t I /-t U$ & 323 \\
\hline$-c A m A$ & 7 & $-m A c ̧$ & 220 & $-v I k /-v U k,-y I k /$ & 81 \\
& 20 & $-m A k$ & $-y U k$ & 28 \\
\hline$-c A n$ & \multicolumn{3}{|r|}{70} & $-(I) z /-(U) z$ & Toplam Türemiş Kelime: 7640 \\
\hline
\end{tabular}

Tablo 3: İsimden Fiil Yapma Ekleri

\begin{tabular}{|l|r|l|r|l|r|}
\hline \multicolumn{1}{|c|}{ Yapım Eki } & $\begin{array}{r}\text { Türemiş } \\
\text { Kelime } \\
\text { Sayısı }\end{array}$ & 143 & $+D A-$ & $\begin{array}{c}\text { Yapım Eki } \\
\text { Kelime } \\
\text { Sayısı }\end{array}$ & $\begin{array}{c}\text { Yüremis Eki } \\
\text { Türemiş } \\
\text { Kelime } \\
\text { Sayıs }\end{array}$ \\
\hline$+A-$ & 94 & $+D I r-/+D U r-$ & 11 & $\begin{array}{l}+(I) m s A-/+(U) \\
m s A-\end{array}$ & 12 \\
\hline$+A l-$ & 5 & $+G A-$ & 8 & $+(I) m s I r A-/+(U)$ \\
$m s U r A-$ & 6 \\
\hline$+A l A-$ & 19 & $+I-/+U-$ & 122 & $+(I) r-/+(U) r-$ & 15 \\
\hline$+A n-$ & 5 & $+(I) k-/+(U) k-$ & 48 & $+(I) r g A-$ & 15 \\
\hline$+A r-(<+g A r-;$ \\
$+A-r-)$
\end{tabular}

Tablo 4: Fiilden Fiil Yapma Ekleri

\begin{tabular}{|c|c|c|c|c|c|}
\hline Yapım Eki & $\begin{array}{c}\text { Türemiş } \\
\text { Kelime } \\
\text { Sayısı }\end{array}$ & Yapım Eki & $\begin{array}{c}\text { Türemiş } \\
\text { Kelime } \\
\text { Sayısı }\end{array}$ & Yapım Eki & $\begin{array}{c}\text { Türemiş } \\
\text { Kelime } \\
\text { Sayıs }\end{array}$ \\
\hline$-A-$ & 52 & -GAlA- & 10 & $-(I) m s I-/-(U) m s U-$ & 6 \\
\hline -AklA- & 40 & $-G I-$ & 10 & -(ü)msūre- & 1 \\
\hline$-A l-$ & 10 & -gIlA- / -gUlA- & 7 & $-(I) n-/-(U) n-$ & 350 \\
\hline -AlA- & 127 & $-G I n-/-G U n-$ & 12 & $-n A s ̧-$ & 24 \\
\hline$-A n-$ & 10 & $-G I r-/-G U r-$ & 8 & $-(I) p-$ & 7 \\
\hline -AnlA- & 21 & -GIt- /-GUt- & 7 & $-p A-$ & 8 \\
\hline$-A r-$ & 38 & $-I-/-U-$ & 54 & $-(I) r-/-(U) r-$ & 55 \\
\hline -ArlA- & 14 & $-(I) k-/-(U) k-$ & 110 & -(I)rgA- & 8 \\
\hline
\end{tabular}




\begin{tabular}{|c|c|c|c|c|c|}
\hline$-A s ̧-$ & 6 & $-(I) k s A-/-(U) k s A-$ & 7 & $-S A-$ & 4 \\
\hline$-A t l A-$ & 7 & -(I)ktIr- / -(U)ktUr- & 8 & $-s I-/-s U-$ & 11 \\
\hline$-c A-$ & 12 & $-(I) l-/-(U) l-$ & 144 & -sIk-/-sUk- & 5 \\
\hline -CAlA- & 16 & $\begin{array}{l}-l A-15 \\
-s I n-/-s U n-\end{array}$ & & & 19 \\
\hline$-C I-/-C U-$ & 19 & $-l A n-$ & 20 & $-s I t-/-s U t-$ & 5 \\
\hline -CIk-/-CUk- & 8 & $-l A s ̧-$ & 13 & $-(I) S_{S-} /-(U)_{S ̧-}$ & 223 \\
\hline$-C I n-/-C U n-$ & 6 & $-m A l A-$ & 16 & -(I)ş̧lA - / -(U)şlA- & 13 \\
\hline$-c ̧-$ & 2 & $-m A n-$ & 8 & -şIr- / -şUr- & 14 \\
\hline$-D A-$ & 12 & -mArlA- & 2 & $-(I) s ̧ t I r-/-(U) s ̧ t U r-$ & 51 \\
\hline -DAlA- & 9 & $-m A s ̧-$ & 18 & $-(I) t-/-(U) t-$ & 340 \\
\hline$-D A r-$ & 14 & -mAzlAn- & 2 & $-y-(<-\underline{d}-)$ & 6 \\
\hline$-D I r-/-D U r-$ & 332 & $\begin{array}{l}-(I) m s A-/-(U) \\
m s A-\end{array}$ & 12 & $-(I) z-/-(U) z-$ & 9 \\
\hline$-G A-$ & 20 & \multicolumn{4}{|c|}{ Toplam Türemiş Kelime: 2417} \\
\hline
\end{tabular}

\section{Yazı Dilinde Bulunmayan Yapım Ekleri}

TTA'da, Türkiye Türkçesi yazı dilinde bulunmayan yaklaşık 140 ek tespit edilmiştir:

İsimden isim yapma ekleri: +AmAç, +AmAk, +ApA, +AdAn, +An, + AnAk, +AnI, +biç, +CAllk, +CAn, +cılah / + culah, + CIllk / +CUlUk, +dAç, $+\mathrm{dAn},+\mathrm{dIk} /+\mathrm{dUk},+\mathrm{dIm} /+\mathrm{dUm},+\mathrm{DIr} /+\mathrm{Dur},+\mathrm{dIrIm} /+\mathrm{dUrUm},+\mathrm{DIrmA}$ / + DUrmA, + eğin (< +egün), +eli, +GAç, +GAn, +GI / +GU, +GIç / +GUç, +GIn / +GUn, +gine, +gIr, +gIl / +gUl, +I / +U, +Iş / +Uş, +kA /+ko, +lA, $+1 \mathrm{Aç},+1 \mathrm{Agg} \mathrm{I},+1 \mathrm{Ag},+$ +Iç / +lUç, +mA, +mAk, +mAl, +mAldAk, +mAt, +mIr / +mUr, +(I)m / +(U)m, +mcak, +mç11, +mIk / +mUk, +(I)msAk, +msAvI, +msUk, +(I)msIrAk, +mtI, +(I)mtlk / +(U)mtUk, +(u)mtul, +mUş, +(I)ntI / $+(\mathrm{U}) \mathrm{ntU},+\mathrm{o},+$ oş, $+(\mathrm{I}) \mathrm{r} /+(\mathrm{U}) \mathrm{r},+\mathrm{sA},+$ sAvI, +sAllk, +sAn, +sIn $/+\mathrm{sUn}$, + sIrAk, $+\mathrm{tA},+\mathrm{y} .$.

Fiilden isim yapma ekleri: -AğI, -AlAç, -AmAt, -AnA, -ArAk, -ArgI, -At, -cAn, -cI, -cIn, -DA, -dAç, -dIç, -dIrIk / -dUrUk, -GIntI / -GUntU, -GIr / -GUr, -lAmA, -mIl, -(I)msAk / -(U)msAk, -msIk / -msUk, -msur, -(I) msIrAk / -(U)msUrAk-, -mAntA, -mAntI, -mIt/-mUt, -nAl, -sAn, -sIn, -vIk / -vUk, -ylk / -yUk...

İsimden fiil yapma ekleri: +AlA-, +CA-, +CI- / +CU-, +CIk- / +CUk-, + cIn- $/+$ cUn-, +DIr- / +DUr-, +GA-, +(I)ksA- / +(U)ksA-, +(I)msIrA- / +(U) msUrA-, +sIr $/+$ sUr , +sIrA- $/+$ sUrA-...

Fiilden fiil yapma ekleri: -AnlA-, -AtlA-, -cA-, -CAlA-, -CI- / -CU-, -DA-, -DAlA-, -GA-, -GAlA-, -GI- / -GU-, -gIlA- / -gUlA-, -GIn- / -GUn-, -GIr- / -GUr-, -GIt- / -GUt-, -1A-, -1An-, -1Aş-, -mAn-, -mArlA-, -(ü) 
msūre-, -nAş-, -pA-, -(I)rgA-, ,-sI- / -sU-, -sIk- / -sUk-, -sIn- / -sUn-, -sIt- / -sUt-, -(I)şlA- / -(U)şlA...

Yazı dilinde görülmeyen bu eklerin bazıları tarihî ve çağdaş lehçelerde de bulunmakta bazıları ise sadece TTA'da yer almaktadır. Hem tarihî hem de çağdaş lehçelerde yer alan eklere, tekrara düşmemek için ilgili başlıklardan sadece birinde yer verilecektir.

\subsection{Tarihî Lehçelerde Görülen Yapım Ekleri}

Tarihî lehçelerde çeşitli kelimeler türetmiş olan bazı yapım ekleri yazı dilinde unutulmuş olmasına rağmen TTA'da varlıklarını korumaktadır. Tarihî lehçelerde bir iki örnekte görülen bazı yapım eklerinin TTA'da korunmuş olması, Türk dili araştırmaları için büyük bir kazançtır. TTA'daki bu ekler ile kurulu kelimeler, Türk dili tarihindeki bazı sorunların çözümüne katk1 sağlayacaktır. Bu eklerden bir kısmı şunlardır:

2.1.1. +AךI: ET'de bir iki kelimede +AjU bk. (Erdal, 1991, s. 163) biçiminde görülen bu ek, TTA'da yer adları, alet adları ve nitelik bildiren sıfatlar türetmektedir:

dişengi/ dişenği "ipe ilmik atılarak hayvanın ağzına yapılan gem” (DS, s. 1524).

düzeøi “iki tepe arasındaki düz yerler, vadi” (DS, s. 1643). krş. TTA düzen aa. (DS, s. 1643).

eteni "şişmanca, etine dolgun" (DS, s. 1798), eteni "toplu, kilolu" (MAS, s. 145).

ġıray1 "kırağı" (GpKA, s. 374).

gözeni "başkasının ilgisini çeken, gösterişli kimse" (DS, s. 2179). krş. TTA gözen/ gözem aa. (DS, s. 2179).

içęü "içli, duygulu, alıngan” (DS, s. 2503).

kılanı "tüyü bozulmuş, kılı çoğalmış tiftik keçi” (DS, s. 4552). krş. TTA kllan aa. (DS, s. 4552).

peseyü "sis" (DS, s. 3502). krş. TTA pösen/ püsen aa. (DS, s. 3502).

2.1.2. +egün: OT'de sadece kökegün "gök sinek" (DLTD, s. 357) kelimesinde görülmektedir. TTA'da birkaç kelimede daha bu ekin olduğunu düşünüyoruz. Ek benzerlik, yakınlık anlamı taşımaktadır:

ètèvinli "şişmanca, etine dolgun" (DS, s. 1798). krş. TTA eteni/ eteyi aa. (DS, s. 4141, MAS, s. 145).

göveğin "sı̆̆ırlara dadanan zar kanatlı bir çeşit sinek" (DS, s. 2167). OT kökegün "gök sinek" (DLTD, s. 357). 
gürevin "kuvvetli, dinç" (DS, s. 2235). krş. TTA güre/ güreli aa. (DS, s. 2235); ET kür "müthiş, sarsılmaz" (ETY, s. 817), OT kür "yiğit, sarsılmaz, yürekli" (DLTD, s. 399).

yalavun "yüksek alev" (DS, s. 4141). krş. TTA yalayı/ yalankl/ yalayu "alev" (DS, s. 4141); < *yal "alev" +agun?

2.1.3. +GAn: ET'de çoğunlukla bitki ve hayvan adları türeten bu ek, "benzerlik, küçültme, yoğunlaştırma" ifade eder (Atalay, 1941, s. 127, 133; Bilgen, 1989, s. 17; Erdal, 1991, s. 87; Biray, 1999, s. 63; Kaçalin, 2006, s. 123):

arpagan "yabani arpa" (DS, s. 330), OT arpagan "arpaya benzeyen bir bitki” (DLTD, s. 36).

çıtırgan "sakızlık ağacına benzer küçük çalı" (MKS, s. 49).

gözgen "kapaksız, küçük dolap" (DS, s. 2181).

güngen "saat, takvim" (DS, s. 2229).

kurugan "ekin içlerinde biten, yemeği yapılan bir bitki" (DS, s. 3011).

özgen "kuzukulağı otunun filizleri” (DS, s. 3372).

pisigen "kedi" (DS, s. 3461).

südgen "kesildiğinde ortasından süt gibi bir sıvı akan; ilaç ve yakacak olarak kullanılan bir bitki, sütleğen" (VGHA, s. 900).

tabışgan / tabışkan "evi beklediği sanılan, fakat görünmeyen, bazı duvardan sesi işitilen hayvan" (DRTA, s. 359). krş. TTA davış/ davuş/ tavuş "ses, hafif gürültü, hışırtı, tıkırtı" (DS, s. 1379, 3846); ET tavış "gürültü, şamata" (EUTS, s. 150); Tel. tabış "ses, haber" (TAS, s. 106).

vıcırgan "bataklık" (DS, s. 4098).

yemişgen "dağda yetişen bir tür meyve" (TIYYA, s. 457).

yengen "elbisenin kolu" (SMYA, s. 431).

yeşilgan "yeşil renkli, kertenkeleye benzer bir hayvan" (DS, s. 4255). krş. TTT yaşılı̀an "yemyeşil" (YTS, s. 238).

2.1.4. +gIl / +gUl: Geometrik şekiller gösteren kelimeler ile renk tonlarını gösteren sifatlar türetir (Ergin, 1990, s. 168; Banguoğlu, 1988, s. 24; Atalay, 1941, s. 135; Räsänen, 1957, s. 98, 1035; Clauson, 2007, s. 190; Erdal, 1991, s. 98):

5 Räsänen, renk tonlarını gösteren ek ile geometrik şekiller türeten eki farklı başlıklar altında incelemiştir. 
dirgll "alacalı, çeşitli renkli" (DS, s. 1469). krş. TTA tarsı "duman rengi" (DS, s. 3835); OT targll "alaca" (DLTD, s. 577), taz "alacalı" (DLTD, s. 591), $<* \operatorname{tar}$ "multicolored, varicolored" + gil (Tekin, 2003b, s. 16).

dörtgül "dört köşe, dört kenarlı" (DS, s. 1588).

içkilli "duygusal, içli" (MAS, s. 237).

kırgıl "kır saçlı insan ya da kır tüylü hayvan" (DS, s. 2818), kırkıl "aklı karal1, kır renkte olan" (DS, s. 2829). OT kırğll "kırçıl" (DLTD, s. 318), TTT kırg̈ll/ kırkıl "saçına, sakalına ak düşmüş, kıranta" (YTS, s. 137).

klzgll "kırmızımtırak renk" (DS, s. 2862).

kurgul "ince, narin" (DS, s. 3007). krş. TTA kırkıl "c1lız kalmış tay" (DS, s. 2829); OT kur "kuru" (DLTD, s. 379).

üçgül "üç köşeli yer; üçgen” (DS, s. 4056). ET üçkil "üçgen” (ETG, s. 305); Krgz. üçkül "üçgen” (KrgzS, s. 793).

2.1.5. +lA: Genellikle zarflara -özellikle zaman zarflarına- gelen bu ek, pekiştirme işlevi taşır (Gabain, 1998, s. 47; Erdal, 1991, s. 403; Taş, 2009, s. 43; Gülsevin, 1997, s. 117; TS-VII, s. 171):

aşamıla "akşamleyin" (ÇADK, s. 159).

çıkla "sadece, yalnız; tamamen; tıpkı, aynı" (DS, s. 1168-1169). ET çak "doğru olarak, tamamıyla, tam" (ETG, s. 271, EUTS, s. 39), OT çak "bir şeyin özünü, aynını gösteren kelime; tam, işte, aynı” (DLTD, s. 131), TTT çak/ çık "tam, tamam; sırf, salt, sade, yalnız, safi, halis" (YTS, s. 49).

çokçala/ çokcalası "çok kez " (DS, s. 1257).

dünle/ dünne "sabah erken, gün ağarmadan" (DS, s. 1631). ET tünle "geceleyin" (ETG, s. 303).

gabala "fazla" (DS, s. 1882). OT kapa "kaba ve iri olan nesne" (DLTD, s. 263), TTT kaba "büyük, iri, kocaman" (YTS, s. 121); TTA ġaba "çok büyük" (EİA, s. 115).

gatla/ katlam "kez" (DS, s. 4537). ET kat "defa, kat" (ETG, s. 278), OT katla "defa, kere" (KTS, s. 132), TTT katla "kat, defa, kere" (YTS, s. 130).

peşinne "peşin olarak" (BYA, s. 212).

sabala "sabahleyin" (DS, s. 4659), sabāla/sabāna/sabālana "sabah vakti, sabah erkenden" (MAS, s. 310).

sıcāla "sıcakta, sıcağın çok olduğu vakit" (MAS, s. 321). 
yenile/ yeyile "şimdi, pek az önce" (DS, s. 4246). OT yayıla "tekrar, yeniden, ikinci defa" (DLTD, s. 742), TTT yenile "yeni, henüz, yeniden, pek yeni" (YTS, s. 242).

yetikle "yetecek kadar" (DS, s. 4257).

2.1.6. +lA $\breve{g} I:$ +lA- eki ile -gI ekinden oluşan birleşik bir ektir. Daha çok alet, organ ve yer adları yapar. Kökteki ismin çok bulunduğu yeri belirtir (Atalay, 1941, s. 188; Aksoy, 1945, s. 246; Kaçalin ve Bilgin, 1997, s. 71-76; Tietze, 2002, s. 230; TS-VII, s. 175). Bazı kelimelerde ekin ikinci ünlüsü, ilk hecedeki geniş ünlünün etkisi ile genişlemiştir:

ayazlağl "rüzgârı kesen, soğuktan koruyan ağaç ya da eğreti çardak" (DS, s. 409).

bağlăgl "duvarların arasına yatay olarak konulan ağaç" (DS, s. 482).

boğazlă̆l/ boğazlağa "huni” (DS, s. 728, 4462).

boklă̆l "hayvan pisliğini taşımaya yarayan kap" (DS, s. 732).

boklağl "hela" (DS, s. 732).

buçukla/ buçuklağa/ buçuklağı “yarım kilelik ölçü” (DS, s. 777).

çamurla/ çamurlağg "okun dingil hizasında durması için altına konulan destek" (DS, s. 1066).

demirlā "sabanda, saban demirinin takıldığı yer" (DS, s. 1418).

domuzla/ donızlağ "su değirmenlerinde çarkın bulunduğu ve döndüğü yer" (DS, s. 1557).

duzlağl "hayvanlara tuz verilen yer" (DS, s. 1615).

götleğe "ot arabasının orta kısmına vurulan ağaç" (DS, s. 2165).

kamuşlağl "kamışlık" (DS, s. 2616).

kaşıkla/ kaşıklă̆ "kaşık konulan sepet, kaşıklık" (DS, s. 2679).

kumlağ "çeşme yollarında birkaç yerde kum toplanması için yapılan engel" (DS, s. 3000).

namazlağl/ namazlavi/ namazlaa "üstünde namaz kılınan kilim, post vb. şeylerden yapılmış seccade" (DS, s. 3236).

pamukla "ladin" (DS, s. 3389).

sokuğlā/soğuklăğ "semizotu” (MAS, s. 329).

tümürlevü "yirmi kiloluk tahıl ölçeğì" (DS, s. 4011).

yarımlağl "on beş kilo buğday alan ve şinik de denilen bir ölçek" (DS, s. 4185). 
2.1.7. +lAn: Tarihî lehçelerde birkaç kelimede tespit edilmiştir (Brockelmann, 1954, s. 118; Atalay, 1941, s. 190). OT'de taylay "ince, güzel, uzun boylu" (DLTD, s. 590) kelimesinde görülen bu ek, Clauson'a (1972) göre Türkçede bilinen bir ek değildir (s. 568-569). TTA'da yer, hayvan ve bitki adları ile küçültme, yakınlık, benzerlik ifade eden sıfatlar türeten işlek bir ektir. Eldeki örnekler farklı kaynaklardan gelen birden çok +1 An ekinin olduğunu göstermektedir:

aklan "beyazca, beyaza yakın; tombul, beyaz" (DS, s. 157).

arklan "ufak ve düzensiz su yolu" (DS, s. 327).

bozlay "bozumsu renkte; kireçli toprak" (DS, s. 752).

çaylan "akarsuların geçit verdiği yer; çakıllı kumlu yer" (DS, s. 1098). OT çaylan "kumlu toprak" (LÇ, s. 150).

dızlay "ağaçsız, çıplak dağ” (DS, s. 1477). TTA daz "otsuz, çıplak arazi, tepe" (DS, s. 1390); OT taz "kel, bitkisiz, çorak" (DLTD, s. 591).

diplen "kısa boylu, şişman" (DS, s. 1511). krş. TTA diplek aa. (DS, s. 1511).

dişlen/ dişley/ dişlān/ dişlank "dişleri dışarı doğru çıkık olan kimse" (DS, s. 1525).

düzlen "düz, ova; yüksekteki düzlük arazi” (ADÜM-I, s. 167, DGBA, s. 468); YUyg. tüzley "vadi, dere, ova" (YUTS, s. 432).

göklen "yeşillik, çimenlik" (DS, s. 2138).

kızlan "killi, çorap toprak; kırmızı topraklı yer; çoğunlukla krom madeni çıkarılan toprak" (DS, s. 2868).

küflen "hayvanların toz ve güneş banyosu yaptığı yer" (OGE, s. 424).

küklen "ilkbahar" (DS, s. 3026). TTA köklem aa. (DS, s. 2952); Krgz. köktöm aa. (KrgzS, s. 499).

özlen "ağaç kökü" (DS, s. 3372), özlem "kimi bitkilerin tohum için uzayan göbek bölümleri” (DS, s. 4631), özlenk "kemik ya da ağacın özü" (DS, s. 3372).

özlen "su kaynağı; küçük dere" (DS, s. 3372). TTA öz "su ark1; dere, çay, ırmak; pınar, derelerin çıktığı yer" (DS, s. 3367); ET öz "vadi” (OTG, s. 251), özek "küçük dere" (EUTS, s. 103).

sazlay "kahverengimsi renkli keçi" (MAS, s. 317).

söpley "oval, yuvarlak" (MAS, s. 333), söplem "yuvarlak, oval biçiminde" (DS, s. 3680), söblen "yumurta biçimi, oval" (DS, s. 3671). TTA söbe/ söbü "yumurta biçimi, oval" (DS, s. 3671); OT subı "uzun ve sivri nesne" (DLTD, s. 536), TTT söbü/ söbe "beyzi, yumurta biçiminde" (YTS, s. 191). 
sulan "bataklık, sazlık, sulu yer" (DS, s. 3691), sulam/ sulamnık aa. (DRTA, s. 345).

2.1.8. +mAk: ET ve OT'de daha çok giysi adları türeten bu ek (Bilgen, 1989, s. 29; Erdal, 1991, s. 110; Tekin, 2003a, s. 84; Kaçalin, 2006, s. 141143) TTA'da küçültme, yakınlık işlevi taşımaktadır. Çeşitli somut adlar ve yakınlık, benzerlik gösteren sıfatlar türetmiştir:

acımak "tarlalarda biten acı, sütlü bir ot" (DS, s. 4405). krş. TTA acımık "sütleğen" (DS, s. 50).

başmak" "ayakkabı, takunya, terlik" (DS, s. 564).

buzmak "koyu mavi" (DS, s. 811).

elcimek "insana alışkın hayvan” (DS, s. 1705), elcimeg aa. (AAS, s. 155). krş. TTA elci/ elcimen aa. (DS, s. 1705).

garmak "kara dut" (DS, s. 4507).

gözmek "çeşme; küçük delik" (DS, s. 2183).

ilikmek "kolay çözülebilen bir çeşit düğüm" (DS, s. 2524).

kartmak "yetişkin, olgun" (DS, s. 2670).

kaşmak "ocağın kemeri" (DS, s. 2680). TTA kaş aa. (DS, s. 2680).

kıtırmak "iyice kızarmış ekmeklerin üzerinden kopan sert ve ince kabuklar; kıkırdak, yumuşak kemiksi madde" (DS, s. 2848).

kismek "küçük fiç" (DS, s. 2884). ET kiz "kap" (ETG, s. 281), OT kiz "kutu, sandık, kap, heybe gibi şeyler" (DLTD, s. 336).

kökmek "kurumuş ya da yıkılmış ağaçların yerde kalan kökü” (DS, s. 2953). oymak "arazinin alçak, çukur yeri” (DS, s. 3302). ET oy "çukur, delik" (EUTS, s. 97).

özmek "tepeler arasındaki çukur, düzlük yer, koyak; bataklık, sazlık yer; kuytu” (DS, s. 3372), özbek "dere, çay, rrmak” (DS, s. 3368). TTA öz "dere, çay, ırmak; tepeler arasındaki çukur, düzlük yer, koyak" (DS, s. 3368); ET öz "vadi" (OTG, s. 251).

portmak "deve yavrusu" (DS, s. 3470). krş. TTA portlak aa. (DS, s. 3470); ET botu "deve yavrusu" (ETG, s. 269).

pusmak "bulutlu, puslu, yağışılı hava" (DS, s. 3489).

6 Etimolojisi karışıktır. Kelimeyi baş köküne bağlayanların yanı sıra kelimenin baş-/ başa"kertik yapmak" fiilinden türediğini iddia edenler de olmuştur. Ramstedt kelimenin Korece palmak "bir tür deri ayakkabı" kelimesinden geldiğini öne sürmüştür (Clauson, 1972, s. 382; Erdal, 1991, s. 110; Tietze, 2002, s. 292; Eren, 1999, s. 43; Gülensoy, 2007, s. 120; Kaçalin, 2006, s. 141; Özkan, 2004, s. 2278). 
sazmak "bataklık, sazlık" (DS, s. 3562).

sekmek "alçak ayaklı, arkalıksız iskemle" (DS, s. 3569). krş. TTA seki/ sekmen aa. (DS, s. 3569); < seki+mek.

tüymek "saç, tel, kıl vb. şeylerin tutamı" (DS, s. 4018).

2.1.9. +(I)mtık / +(u)mtuk: +(I)mtI ekinin genişlemiş şeklidir. TTT'de birkaç kelimede görülen ek, bugün Kuzey grubu Türk lehçelerinde ve Türkmen Türkçesinde de yaşamaktadır (Banguoğlu, 2004, s. 179; Banguoğlu, 1988, s. 17; Deny, 1941, s. 313; Biray, 1999, s. 54; Güner Dilek, 2007, s. 1021; Kasapoğlu Çengel, 2005, s. 118; TS-VII, s. 33):

bozumtuk "boza çalar renk" (DS, s. 753).

karamtık kızll "siyahla kırmızı arası bir renk" (DS, s. 2651).

2.1.10. -dAç (< -DAçI) : ET'de -An ve -AcAk sıfat-fiil ekleri ile aynı işlevde kullanılan ve işi yapanı bildiren -DAçI ekinden gelişmiştir. -DAçI, ET'de işlek olmasına rağmen zamanla unutulmuş, yerini başka ekler almıştır (Gabain, 1988, s. 55; Räsänen, 1957, s. 120; Mansuroğlu, 1956, s. 105; Eraslan, 1980, s. 37, 62; TS-VII, s. 73; Gülsevin, 1997, s. 124). Ek, Türkmen Türkçesinde birkaç kalıcı isim türetmiştir: girdeçi "kazanç", çıkdaçı "masraf" (Biray, 1999, s. 192). Mişer Tatar Türkçesinde bul- (ol-) fiiline eklenerek s1fat-fiil işlevi ile kullanılmaktadır (Alkaya, 2014b, s. 39):

andaç/ andaş "hatıra, hediye, armağan" (DS, s. 256), andaç "sülale ve nesli devam ettiren evlat" (OAAD, s. 247), andaç "ölen kimsenin arkada kalan tek evladı; ölmüş aile büyüklerinin hatırası sayılan insan veya eşya; evlat, nesil, döl; isim, ün, şöhret” (DS, s. 256).

doğdaç/ doğdaş “yeni doğmuş bebek" (DS, s. 1536, 4486). TTT dog்dacı "doğacak olan" (YTS, s. 71).

geldeç "gelecek zaman" (DS, s. 1973). TTT geldeç "gelecek" (YTS, s. 90).

oldacl/oldaç "şişman, büyümeye, gelişmeye elverişli olan” (DS, s. 3277), oldeş "gelişmiş, iri yarı" (AAS, s. 258).

ondaç "gürbüz, gelişmiş" (DS, s. 3283).

2.1.11. -mAntI: Osmanlı Türkçesinde sadece soymantı ( soymandı) kelimesinde görülür (Atalay, 1941, s. 206; Gülsevin, 1993, s. 94). Ekin -mA eki ile +(I)ntI veya -mAn ile +tI eklerinin birleşmesinden oluştuğu düşünülebilir. TTA'da, çoğunlukla aşağılama anlamı taşıyan adlar ve sıfatlar ile parça, artık anlamı taşıyan adlar türetmiştir. Kök ünlüsü dar olan iki kelimede ekin ilk ünlüsü daralmıştır:

dırmıntı "ürün toplandıktan sonra geriye kalan ve tırmıkla toplanan döküntüler” (DS, s. 1471). 
kesmenti "kesilmiş odun parçası, iri sopa" (DS, s. 2767).

örtmantı "küçük, ekleme, uydurma ev" (MAS, s. 298).

soymantı "sopa" (DS, s. 3670), soymantı "soyulmuş saz yaprăğ; kübür, artık" (BYA, s. 223), soymaltı "soyulmuş meşe kütüğü" (DS, s. 3670). TTT soymantı "sopa, değnek, asa" (YTS, s. 191), soymantı "hıyar gibi soyulup yenilen şeyler; hıyar ve meyve gibi şeylerin kabukları" (Gülsevin, 1993, s. 94).

türmüntü "beceriksiz, aptal" (DS, s. 4014).

yaymantı "dağınık öteberi” (DS, s. 4213).

yeymenti "hayvan yiyeceği”" (MAS, s. 392).

yozmantı "terbiyesiz" (DS, s. 4304). TTA yoz- "huyu bozulmak, sevimsizleşmek" (DS, s. 4304).

2.1.12. -GIr- / -GUr-: ET'den beri kullanılan ettirgenlik eklerinden biridir. Batı Türkçesinde donmuş birkaç örnekte 18. yüzyıla kadar varlığını korumuş, daha sonra yerini başka eklere bırakmıştır. Doğu ve Kuzey grubu Türk lehçelerinde ise az işlek olup varlığını sürdürmektedir (Gabain, 1988, s. 59; Erdal, 1991, s. 748; Räsänen, 1957, s. 157; Gülsevin 1997, s. 140; Hacieminoğlu, 1992, s. 109; Güngördü, 1998, s. 215; Öztürk, 1997, s. 91):

dalgır- "kaynamak; şen şakrak olmak" (DS, s. 1344). TTA dal- "kaynamaya başlamak" (DS, s. 1344).

ergür- "ulaştırmak" (DS, s. 1769).

eşgirt-/ eşgir- "koşmak, seğirtmek" (DS, s. 1792). TTA eş- "hareket etmek, yola çıkmak" (DS, s. 1795); ET eş- "at eşkin gitmek, atı eşkin sürmek" (OTG, s. 243).

turgur- "bir işi başkasının yardımıyla yapmak" (DS, s. 3994).

ürgür- "hamur mayalamak" (DS, s. 4069). krş. TTA ürgüt "hamur mayası" (DS, s. 4072), ördürme "maya çoğaltma" (DS, s. 4625).

2.1.13. -sIk- / -sUk-: ET'de edilgen çatı kuran ve nadir kullanılan ek, Batı Türkçesinde unutulmuştur. Pekiştirme anlamı taşır (Deny, 1941, s. 490; Gabain, 1988, s. 60; Çağatay, 1967, s. 45; Bilgen, 1989, s. 133; Tekin, 1992, s. 87; Eraslan, 1996, s. 57):

bōsuk- "boğulmak" (DS, s. 742).

çavzık- "güçlüğ̈̈ yenmek için oraya buraya koşturmak, bocaladığını gösteren davranışta bulunmak" (DS, s. 4476), cavzık- "işi uzatmak, yarıda bırakmak, usanarak işten kaçmaya çalışmak" (DS, s. 867). TTA çav- "amaçtan şaşmak, yol değiştirmek; ivmek, çabalamak; dolaşmak, gezmek" (DS, s. 1095); TTT çav- "ileri firlamak, istikametini değiştirmek, sapmak" (YTS, s. 52). 
yavsuk- "ezilip büzülerek, yalvarıcı bir tavırla durumunu anlatmak" (DS, s. 4205). krş. TTA yavuncu-/yavinca-/yavincık-/yavınç ol- aa. (DS, s. 4205), yavınst- "yakınarak yalvarmak" (DS, s. 4816); krş. Krgz. cagın- "yaltaklanmak, hoşa gitmeye çalışmak, yaranmak" (KrgzS, s. 162).

ylğsık- "irkilmek, duraklamak; sürünün ürkmek ya da çullanmak neticesi üst üste binmesi" (DS, s. 4263; KABK, s. 706; BKHK, s. 103); OT yıg- "birşeye engel olmak, alıkoymak", ylg̈ıl- "çekinmek, kaçınmak" (DLTD, s. 779, 780).

yorsuk- "biraz yorulmak" (MAS, s. 396).

\section{2. Çağdaş Lehçelerde Görülen Yapım Ekleri}

Yazı dilinde görülmeyen bazı ekler çağdaş lehçelerde benzer işlevlerle yer almaktadır. TTA'daki bazı eklerin Hakas, Altay Türkçeleri gibi uzak lehçelerde de görülmesi dikkat çekicidir.

2.2.1.. +CAn: Kuvvetli bir eğilimi, bir özelliği veya kabiliyeti ifade eden sıfatlar türeten bu ek, çağdaş Türk lehçelerinin çoğunda mevcuttur: işçen "çalışkan, gayretli", izçen "iz süren", oyçan "düşünceli", sözçen "geveze", boyçan "uzun boylu", öyçan "evine bağlı, evini seven", akuvçan "akışkan, akıcı", hövescey "hevesli", ārcay "namuslu" (Räsänen, 1957, s. 93; Clauson, 2007, s. 194; Çeneli, 1997, s. 1; Biray, 1999, s. 79; Koraş, 1998, s. 50; Kasapoğlu Çengel, 2005, s. 108; Alkaya, 2008, s. 212):

alavçan "sert mizaçlı" (DS, s. 202).

darıcan "serçeden biraz büyük, boz renkli, boynu kırmızılı, kışın gitmeyen yerli kuş" (DS, s. 1371), darcan/ daracan/ darlcan/ darllcan "serçe" (DS, s. 1369).

dilcan "geveze" (DS, s. 1492).

gilcan "ince yap1lı" (DS, s. 2039).

gökcen "güzel insan" (DS, s. 2136).

kekecen "kekeme, peltek" (DS, s. 2722).

kekilcen "tekesakalı da denilen, çiğ yenen bir kır bitkisi” (DS, s. 2722).

kılçan "seyrek saçlı" (DS, s. 2794).

kılçan "tavuklara dadanan bir hayvan, gelincik" (DS, s. 2794).

kumcan "kumda yaşayan küçük kayabalığı" (DS, s. 2999).

sütlücen "bir çeşit ilkbahar bitkisi” (DS, s. 3727).

tekercen "yenilebilir bir çeşit yabanıl ot” (DS, s. 3863). 
yircen "tehlike anında pis koku yayarak kendini koruyan bir hayvan" (EYDS, s. 252). krş. TTA yercegöğce "kokarca" (DS, s. 4249), yiğir yiğir "pis pis (koku için)" (DS, s. 4277). TTA yiğg- "çürümüş nesne kötü kokmak"

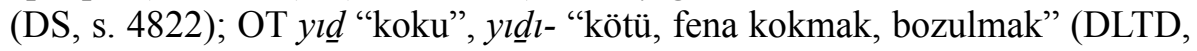
s. 779). < yiğir+cen.

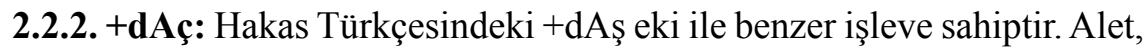
nesne adları türetir: Hak. emdeş "omuza asılan ve içine şerbetçi otu konulan torba", pilektes "bilezik", purundos "atların burunlarına takılan torba", kiptes "kalpak, şapka" (Kara, 2005, s. 67-68):?

çı̆̆daç "süt kazanlarının üzerini kapatmak için kamıştan yapılan örtü” (DS, s. 1152). TTA çı̆̆ aa. (DS, s. 1152).

eldeç "mısır, buğday gibi tahılları dövmekte kullanılan taş ya da ağaçtan yapılmış dibek tokmăğ" (DS, s. 1707).

yağdaç "lamba" (DS, s. 4118).

2.2.3. +DIr / +Dur: Yaz1 dilinde bulunmayan bu ek (Atalay, 1941, s. 87, 90), Hakas Türkçesindeki +dIr eki ile benzerlik taşımaktadır: Hak. piltir "beyaz yan böğürlü, belli (< pil 'bel')", xondır "hayvanların kaybolmaması için takılan çan (< hon 'yansıma')" (Kara, 2005, s. 77-78). Genellikle yansıma kökler üzerine gelen ekin yapısı açık değildir. Ekin çoğunlukla sıfat türettiği görülmektedir:

beldir "patlak gözlü" (DS, s. 608), beldir beldir "manası, aptal aptal bakmayı anlatmak için; canlı ve dikkatli bakışı anlatmak için" (DS, s. 608).

çındır "sinir; sinirli ve köpüklü et" (SMA, s. 281; DS, s. 1179). krş. TTA clyındırık/ cındırık/ çı̆̆ındırık "sinirli, yağsız et" (DS, s. 945).

çildir "teninin rengi çil renginde olan kimse" (DS, s. 1214).

çondur "c1lız" (DS, s. 1268). krş. TTA çandır "c1lız; ince, uzun bacaklı insan" (DS, s. 1068), çönez/ çonaz "c1lız, sıska çocuk; büyümemiş, kurumuş ağaç" (KA, s. 206).

çönetir "sakat" (DS, s. 1228). krş. TTA çona "parmakları açılmayan kimse" (DS, s. 1268).

deliştir "oturduğu kalktığg yeri bilmeyen" (BnİA 165).

diştir "ön dişleri dişarıya doğru firlak olan kimse" (DS, s. 1525).

hoydur "başıboş, serseri" (DS, s. 2422).

7 Kara, bu kelimelerdeki eki ortaklık ve beraberlik bildiren + dAş eki ile aynı kabul etmiş ve ekin nesne isimleri yapma işlevi de taşıdığını iddia etmiştir. 
iğdir "hastalıklı, c1lız, çok zayıf" (DS, s. 2509). TTA ĭg "hastalık, dert" (DS, s. 2508); ET ig "hastalık" (ETG, s. 274).

mandır mandır "şaşkın şaşkın" (DS, s. 3120).

2.2.4. +gIr: Tarihî ve çağdaş lehçelerin bir kısmında nadir görülen bu ek, "sahip olma, gibilik, benzerlik" ifade eden sifatlar türetmiştir: Özb. tengqur "yaşıt, akran", Alt. bozıtkır "sert adımlı at", oygor "bilge, akıllı", üngür "sedalı, tonlu", Tuv. dilgır "konuşkan, dilbaz", sütkür "sütü bol", işkir "içli, içi geniş", okkur "ok gibi hızlı" (Atalay, 1941, s. 183; Kaçalin, 2006, s. 149-151; Arıkoğlu, 2007, s. 1164; Güner Dilek, 2007, s. 1022; Koraş, 1998, s. 103; Coşkun, 2000, s. 36):

dazkır "saçsız, kel" (MİA, s. 396).

dişgir "dişli, hasmına yenilmeyen" (MKS, s. 61).

işgir/ işingir "becerikli" (DS, s. 2563).

keşgir "sevinç, neşe" (DS, s. 2771). krş. TTA keşlen- "alay etmek, eğlenmek" (DS, s. 2772).

mızgır "geveze, sıkıcı konuşan" (DS, s. 4596).

taşgır $r^{8}$ "taş ev" (DS, s. 3840)?

2.2.5. +lAç: Türk dilinde nadir görülen isimden isim yapma eklerinden biridir: yıllaç "senelik, yıllık", etleç "etli olan kimse", gü̈leç "boğuk", köseleç "köse gibi", kartlaç "moruk" (Atalay, 1941, s. 187, 193; Brockelmann, 1954, s. 117; Tabaklar, 1994, s. 14; Ganiyev, 2013, s. 93). Küçültme ve benzerlik ifade eder:

abalac "sevici kadın" (DS, s. 6), ablaç aa. (AA, s. 26). krş. TTA ablacı aa. (DS, s. 23).

babalaç "iri, büyük (insan veya hayvan)" (DS, s. 450).

bitleş "bitli" (DS, s. 711).

gartlaç "yaşlı, ihtiyar; yenme zamanı geçmiş, sertleşmiş, taze olmayan bitki” (DS, s. 1930), kartalaç "kart, yaşlı" (DS, s. 2670).

gezleç "ikinci kez yavrulayan koyun" (EYDS, s. 108). krş. TTA gez "bir yaşında keçi, oğlak" (DS, s. 2019).

gızlaç "çok sıcak yer" (MAS, s. 190), kızlaç "sıkıntılı, havasız yer" (DS, s. 2868).

gödeleç “boyu kısa, geniş karınlı küp” (DS, s. 2124).

kızlaç "sıcağa dayanıklı bir çeşit kızıl toprak” (DS, s. 2868).

8 Belki Farsça kārgîr' in etkisiyle. 
kuzleç "güneş görmeyen, gölgeli yer" (DS, s. 3021). TTA guz "gölgelik, güneş almayan yer" (DS, s. 2204); ET kuz "bir dağın kuzey yamaçları" (OTG, s. 249).

sapalaç "ters yol" (DS, s. 3539).

tokalaç "bodur, şişman çocuk" (DS, s. 4765).

ylllaç "yılını doldurmuş saka vb. kafes kuşu” (DS, s. 4271).

2.2.6. +mA: Ek, bazı Türk lehçelerinde birkaç kelimede görülmektedir. Küçültme, benzerlik, yakınlık ve pekiştirme işlevi taşımaktadır: Çağ. özme "kendisini bilir", gölme "havuz, gölcük", Hak. sispe "kazık", köspe "sihirli ayna, televizyon" (Kaçalin, 2011, s. 988; Serebrennikov ve Gadjieva, 2011, s. 98; Kara, 2005, s. 25). ${ }^{9}$ Ek, Sibirya Tatar Türkçesinde renk adlarına gelerek eklendiği kelimeye benzerlik, yaklaşıklık anlamı katmaktadır: quyırma "kahverengimsi", kügiltirme "mavimsi" (Alkaya, 2008, s. 219):

gölpe "havuz" (DS, s. 4510). Krgz. kölmö "durgun su, durgun suyun irkileceği yer" (KrgzS, s. 500).

gürempe "çalılık, ormanlık" (DS, s. 2233). TTA güre "sık, gür” (DS, s. 2235).

kırma "ot bitmeyen bayır yer; engebeli toprak; dağ ve tepelerdeki kuytu yerler" (DS, s. 2833).

özmelik "sı çalılık" (DS, s. 3372). TTA öz "sulak, verimli yer, otlak" (DS, s. 3368); ET öz "vadi” (OTG, s. 251).

pepeme "kekeme" (DS, s. 3427).

2.2.7. +mçıl: Benzerlik ifade eden ek, Mişer Tatar Türkçesinde karamcıl kelimesinde vardır (Alkaya, 2014a, s. 207). TTA'da da bu ekle türetilmiş tek örnek tespit edilmiştir:

sarımçıl "sarımtırak" (BİA, s. 698).

2.2.8. +msAvI: +sAvI ( $<+$ sAğI) eki ile aynı işleve sahip olan ekin Azerbaycan Türkçesinde +(I)msov şekli de vardır (Biray, 1999, s. 55; Kartallığlu ve Yıldırım, 2007, s. 186) (bk. +sAvI):

delimsā "çıllgın, delişmen" (EYDS, s. 68), delümsō "deli gibi, delice" (AybA, s. 125).

kekremsevi "kekremsi, acımtırak" (KkA, s. 217).

kırmızımsavl "kırmızımsı" (KA, s. 507).

9 Örneklere Azerbaycan Türkçesinden şu kelime de eklenebilir: qarınpa "çoxyeyen" (ADDL, s. 283). 
2.2.9. $+(\mathbf{u})$ mtul: $+(\mathrm{I}) \mathrm{mt}$ tk eki ile aynı işlevi taşıyan ek, Azerbaycan ve Türkmen Türkçelerinde görülür. Doğu grubu Türk lehçelerinde daha yaygındır (Banguoğlu, 2004, s. 179; Banguoğlu, 1988, s. 18; Atalay, 1941, s. 153; Deny, 1941, s. 313; Eckmann, 2009, s. 50; Biray, 1999, s. 54; Koraş, 1998, s. 147). Doğu Türkçesinde daha nadir olarak ekin yalın biçimine de rastlanır: aktul, köktül, kumtul (Banguoğlu, 1988, s. 18). Özbek Türkçesinde ekin +(I) mtIr şekli de vardır (Koraş, 1998, s. 147):

bozumtul "boza çalar renk" (DS, s. 753).

karamtul dikeni "50-70 cm yüksekliğinde dikenli bir çalı" (DADK, s. 11).

2.2.10. +sAy: Ad ve sıfatlara gelerek çoğunlukla sıfat türetir. Nadir bir ektir: boysan "levent, uzun boylu" (Atalay, 1941, s. 238; Kocasavaş, 1998, s. 427). + sAk eki ile benzer bir işlev taşımaktadır:

çiğsey "tam kaynamamış, iyice pişmemiş" (MAS, s. 90).

delisen "sersem, salak, çılgın, delişmen" (DS, s. 1413).

kocasan "yaşlı görünüşlü (kimse)" (DS, s. 2892), gocasan "yaşlı görünen" (EYDS, s. 116).

milsen "milli toprak" (DS, s. 3199).

özsen "uygun, yerinde, yakışık alan" (DS, s. 3373).

susay "tatsız, su tadında, su gibi” (DS, s. 4709, AOA, s. 490).

yelsen "yel" (DS, s. 4240).

2.2.11. +sAvI (<+sĂğI): Tarihî ve çağdaş lehçelerde nadir görülen bu ek, +(I)msI eki ile aynı işlevde kullanılır, küçültme ve benzerlik bildirir. TTT'de sadece renk adlarıyla kullanılmıştır. Bazı çağdaş lehçelerde nitelik bildiren sıfatlara da eklenmektedir (Banguoğlu, 1988, s. 26; Aksoy, 1945, s. 264; Kaymaz, 2000, s. 330; TS-VII, s. 250, DS, s. 3594, 4673). Azerbaycan ve Türkmen Türkçesinde $+\operatorname{sov}^{10}$ (Biray, 1999, s. 55), Tatar Türkçesinde + sUv (Ganiyev, 2013, s. 206), Karakalpak Türkçesinde +sAv (Räsänen 1957, s. 111) şeklinde görülmektedir. Azerbaycan Türkçesinde ekin +(I)msov şekli de vardır (Biray, 1999, s. 55; Kartallığlu ve Yıldırım, 2007, s. 186). Bazı örneklerde, ilk hecedeki geniş ünlünün etkisi ile ekin ikinci ünlüsü genişlemiştir: 938).

ă̆asevi "ağa gibi hareket eden ve bu şekilde olmayı seven kişi” (KİA, s.

ayrıksağa/ ayrıksa/ ayruksağu "başka, bambaşka, apayrı, kimseye benzemeyen, acayip" (DS, s. 430).

10 Ercilasun'a göre Azerbaycan Türkçesindeki +sov eki, ET +slg'dan gelmektedir: + slg > $+\operatorname{slw}>\operatorname{sov}(2007$, s. 13). 
cünütsevi "batakl1k" (DS, s. 1027). TTA cünüt aa. (DS, s. 1027).

delisevi "delice" (AYA, s. 764).

demirseyi "demirimsi" (DSİ, s. 182).

erkeksavı "erkeğe benzer (aşağısamak, onur kırmak amacıyla kullanılır)" (KA, s. 260).

eşgisevi "eşkice" (AYA, s. 766).

gambirsevi "kambur gibi" (YYA, s. 150).

kadınsavı "kadınımsı, kadını andırır, kadın gibi" (KA, s. 361).

kıraçsevi "kıracımsı, kıraca benzer" (AA, s. 590).

kızılsavu "kızıla çalan renk, kızılımsı" (DS, s. 2866).

kumsavı "kuma benzer bir çeşit toprak" (DS, s. 3000), gumsav1 "kumu çok olan toprak" (KMİA, s. 392), gumsevi "kumlu, kumu daha çok toprak" (AA, s. 366).

uzunsav "uzun boylu, uzunca" (VGHA, s. 220).

zenginsevi "zengince, biraz zengin" (EYDS, s. 204).

2.2.12. +sIrAk: İsimden fiil yapan + sIrA- eki ile fiilden isim yapan $-\mathrm{k}$ ekinin birleşmesi ile oluşmuştur. İstek, düşkünlük anlamı taşıyan kelimeler türetmiştir. Ek, Kırgız Türkçesinde de düşkünlük anlamı ile kullanılmaktadır: çaysıraak "çayçıl (çay içmeyi seven, çay tiryakisi)" (KrgzS, s. 257):

boğazsırak" "obur (hayvan hakkında)" (DS, s. 728).

çenesirek"geveze" (AOA, s. 463).

koçsırak ol- "dişi koyun, erkek koyun istemek" (DS, s. 2895).

2.2.13. -GIntI / -GUntU: Tietze (2002), bu eki -(I)ntI ile aynı kabul etmiş, -GIntI yapısın1, -GIn ile kurulu isimlerin etkisine bağlamıştır (s. 378). İkinci bir ihtimal olarak ekin -GIn eki ile aşağılama, küçültme bildiren +tI ekininin birleşmesinden meydana geldiği düşünülebilir. Ek, çağdaş lehçelerin bir kısmında görülmektedir: Özb. kelgindi "yerli olmayan, yabancı", quvğundl "sürgün" (Coşkun, 2000, s. 54), Az. basgıntı "baskın; çapul, yağma, soygun" (ATBS, s. 64), gisgıntı "gözdağı verme, korkutma" (ATBS, s. 368):

askıntı "sırnaşık, asalak (kimse)" (DS, s. 4425).

azgıntı "soytar1, serseri" (DS, s. 4389).

depginti "üzümün ayakla ezilerek şırasının çıkarıldığı, tabuta benzeyen araç" (NYA, s. 249).

katgıntı "karış1k tohum" (DS, s. 2682). 
sepkinti “yağmur çisentisi” (KYA, s. 251).

soyğuntu "soygun malı" (DS, s. 3669).

üzgüntü “üzüntü” (BYA, s. 240).

yapgintı "petek" (MAS, s.383). krş. TTA yapl/ yapgl "bal peteği" (DS, s. 4176).

yuykuntu "bulaşık yıkanan kap" (DS, s. 4826). TTA yuğ-/ yuy-/ yu- "y1kamak" (DS, s. 4314); ET yu- "y1kamak" (ETG, s. 313), TTT yu-/ yuğ-/ yuy"yıkamak" (YTS, s. 252).

2.2.14. -GIr / -GUr: İlk defa Çağatay Türkçesinde görülen bu ek, çağdaş lehçelerin pek çoğunda bulunmaktadır. Genellikle tek heceli kelimelere eklenerek yoğun bir özelliği ve eğilimi ifade eder, düşkünlük bildiren sıfatlar türetir: çalışkır "çok çalışkan", ötkür "keskin", sezgir "hassas", akgır "hızlı akan", bilgir "bilgiç" (Atalay, 1941, s. 139; Räsänen, 1957, s. 130; Eckmann, 2009, s. 52; Çeneli, 1997, s. 24; Koraş, 1998, s. 257; Biray, 1999, s. 183; Ceritoğlu, 1998, s. 66; Alkaya, 2008, s. 231). TTA'da alet adları da türetmektedir:

açkır "anahtar" (DS, s. 60).

çalgır/çalg̈ır/çalg̀ur "gelinlerin başlarına bağlanıp ucu arkadan ucu aşağıya sarkıtılan örtü” (DS, s. 1053, GKA, s. 449), çelgir "alna bağlanan yazma” (DS, s. 1122). TTA çal- "sarmak, dolamak" (KYAS, s. 52).

eşkir "iyi koşan at" (DİAS, s. 133). ET eş- "at eşkin gitmek, at1 eşkin sürmek" (OTG, s. 243).

koygur "etkili, dokunaklı, acıklı, içli (ses, şarkı vb.)" (MİAS, s. 207).

örkir "iyi iş yapan” (DS, s. 3348). krş. TTA ör-/ örü- "yapmak” (DS, s. 3348).

yangır "yanık, etkin ses, söz" (DS, s. 4166).

2.2.15. -mIt / -mUt: Çağdaş lehçelerden sadece Türkmen Türkçesinde tespit edilmiştir. Fiillerden soyut ve somut isimler türetir, işlek değildir: Trkm. almıt "para, mükâfat; cevap" , iymit "yiyecek, yemek, gıda" (Biray, 1999, s. 185; Tabaklar, 1994, s. 33; Kara, 2001, s. 32). Tietze, ekin -mIk eki ile ilgi olduğunu iddia etmiştir (2002, s. 493). TTA'daki örnekler, Tietze'yi desteklemektedir:

çedlemid "çitlembik" (KBLG, s. 521).

kırmıt "ağaç kırıntıları; küçük parçalar halinde" (DS, s. 2834, TKYA, s. 185). krş. TTA kırmıh "kıymık, yonga, ufak tahta parçası" (PTK, s. 282), ġırmik "ağaç kabuğu” (EYSV, s. 89). 
kürmüt "herhangi bir şeyi sıyırmak veya evin damında biriken karı atmak için kullanılan tahta araç" (SIYYA, s. 661).

balamurt "taze ve olgun incir" (DS, s. 499). krş. TTA balaran/ balargın/ balarlk/ balartt/ balart aa. (DS, s. 499). < *balar- (< bal+ar-) "ballanmak, tatlilaşmak" -mu(r)t?

2.2.16. +CI- / +CU-: Bazı çağdaş lehçelerde oluş bildiren geçişsiz fiiller türetir. Yansıma kelimelerden de yeni kelimeler türeten bu ekin lehçelerde

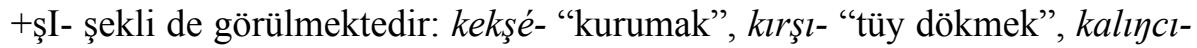
"sıklaşmak, koyulaşmak", terşi- "hafifçe terlemek" (Güngördü, 1998, s. 101; Gündördü, 2002, s. 174; Ceritoğlu, 1998, s. 169; Kasapoğlu Çengel, 2005, s. 126; Ganiyev, 2013, s. 165; Uygur, 2010, s. 110; Güner Dilek, 2007, s. 1028; Öztürk, 1997, s. 68). TTA'da ekin -n- ve -k- fiilden fiil yapma ekleri ile genişlemiş şekilleri de görülmektedir:

buncuk- "sıkılmak, daralmak, sabrı kalmamak" (DS, s. 792), buncık- "çok acıkmak" (DS, s. 792). ET buך "yokluk, dert, sikıntı" (OTG, s. 242).

carcın- "bağırmak, çağırmak" (TiYA, s. 448).

derci- "biri hakkında şikâyette bulunmak, dert yanmak" (SIYYA, s. 595), derçik- "içini boşaltmak" (DS, s. 1431); krş. TTA dertsin- "dert yanmak" (KmYA, s. 271); < dert+ci-.

evci- "evinin işine ve eksiklerine düşkün olmak, eksiklerini tamamlamaya çalışmak; herhangi bir hayvan eve alışmak, evcilleşmek" (DS, s. 1801).

gancık- "insanın bir yeri bir şey arasında sıkışarak kan toplamak" (DS, s. 1909). krş. Az. gançır "bertik, morartı, çürük" (ATBS, s. 312).

huycuk- "kuşkuyu huy haline getirmek, ürkmek" (KA, s. 337).

hümcün- "dövmeye kalkışmak" (DS, s. 2450).

kapçı- "ceviz, badem gibi meyvelerin üstündeki yeşil kabuk soyulmak" (DS, s. 2632).

kırcl- "kışın soğuk havalarda ufak ve sert taneli kar serpiştirmek" (DS, s. 2818), kırçl- "ince ince yağmur yağmak; ince ince kar yağmak" (DS, s. 2819).

kircik- "kirlenmek; gücenmek; darılmak" (DS, s. 2875).

körcük- "eski neşesini yitirmek, karamsar olmak" (KA, s. 415).

lemci- "kirden kokmak" (DS, s. 3072). lem < nem.

morcu-, $s$. "yıkandığında iyi ağarmayan beyaz çamaşırlar kirli bir renk almak" (MKS, s. 119), morcuh- aa. (KMİA, s. 465), morcuk- aa. (KA, s. 455). 
tercik- "hafif terlemek" (MAS, s. 355), terci- "kışın güneşli günlerde kar erimeye başlamak" (DS, s. 4753). TTT derci- "terler gibi olmak" (YTS, s. 65); krş. TTA tersi- "hafifçe terlemek" (DS, s. 3894).

2.2.17. +(I)msIrA- / +(U)msUrA-: Bazı lehçelerde birkaç kelime türetmiş olan bu ekin fiilden fiil yapan -(I)msIrA- ekinden örnekseme yoluyla oluştuğu düşünülebilir (Çeneli 1977, s. 44; Hacieminoğlu, 1992, s. 253) (krş. +(I)msA-). Ek "istek" ve "gibi saymak, öyle kabul etmek" anlamını taşıyan fiiller türetmiştir. TTA' da bu ek ile kurulu kelimelerin tamamı Acıpayam (Denizli)'dan derlenmiştir:

azımsıra- "verilen ücreti az bulmak" (DADK, s. 15).

benimsire- "akrabalığını göstermek, yakınlık göstermek; kendine yakın bulmak" (DADK, s. 16).

bizimsire- "akrabalığını göstermek, yakınlık göstermek" (DADK, s. 16).

gögüumsüre- "yeşilliğe ve ota özlem duymak" (DS, s. 2133).

kötümsüre- "kötülemek, daha kibar bir dille kötülemek" (DADK, s. 36).

küçümsüre- "küçük görmek, altalamak" (DADK, s. 36).

2.2.18. +sIrA-: ET'de "birşeyden yoksun olmak" anlamında fiiller türeten +sIrA- eki (Gabain, 1988, s. 50; Taş, 2009, s. 108; Tekin, 1992, s. 83) ile karıştırılan bir ektir. Türkmen Türkçesi ile Doğu ve Kuzey grubu lehçelerde arzu bildirme işlevi ile kullanılmaktadır (Räsänen, 1957, s. 151; Öztürk, 2015, s. 37; Arıkoğlu, 1996, s. 52; İlker, 1997, s. 64; Ceritoğlu, 1998, s. 172; Güngördü, 1998, s. 152; Söyegow vd., 1999, s. 213; Hanser, 2003, s. 163). Ek, TTA'da arzu, istek ifade eden +sA- ile benzerlik, yakınlık anlamı taşıyan +sIekinin işlevi ile kullanılmaktadır. Bir örnekte ekin ikinci ünlüsü daralmıştır:

aylbsırt- "ayıplamak" (SMYA, s. 152).

çĭgsire- "sıcakken üst üste konulan ekmek bozulmağa, kokmağa başlamak" (DS, s. 1211). krş. TTA çiğsi- aa. (MAS, s. 90).

etsire- "etsiz kalmak, uzun süredir et yemediğinden et yemek istemek" (MAS, s. 146).

eysire- "dinlenme zamanı gelmek" (DS, s. 4502).

gatıksıra- "tuluma basılan çökelek, peynir yiyecek kıvamına gelmek, acımak" (MAS, s. 167). krş. TTA katıksı- "peynir, çökelek, yağ vb. yiyecekler tuzlanarak yenecek duruma gelmek" (DS, s. 2683).

gaysıra- "ekmeğin lastik gibi olması, yanmaya yüz tutması" (AAS, s. 179). krş. TTA gay "ekili olan tarlada, tohumun toprak üstüne çıkmasına engel olan sertleşmiş kısım” (DS, s. 1942). 
koçsıra- "dişi koyun erkeği ile çiftleşmek" (DS, s. 2895).

susura- "susamak" (DS, s. 3701).

2.2.19. -CAIA-: -CA- ekinin sıklık fiilleri yapan -AlA- ekiyle kaynaşmasından oluşmuş birleşik bir ektir. Türkmen Türkçesinde ve Kuzey grubu Türk lehçelerinde (Söyegow vd., 1999, s. 212; Güngördü, 2009, s. 587) görülen bu $e k$, işlek değildir:

boğcala- "tırmalamak; örselemek, grrtlağını sıkmak, eziyet etmek" (DS, s. 728).

gevçele- "yemeye, çiğnemeye çalışmak" (DS, s. 2008).

govcala- "kovalamak" (HKTS, s. 123, KbrA, s. 306).

kapçala- "yakalamak, tutmak" (DS, s. 2631).

kürcele- "firlatmak" (DS, s. 4577).

ovcala- "bir şeyi avuçta sıkarak ezmek, ovalamak, ufalamak" (DS, s. 3299).

yumcala- "s1kmak, tartaklamak" (DS, s. 4315).

2.2.20. -DAIA-: -DA- eki ile -AlA- ekinin birleşmesinden oluşmuştur. Genellikle sıklık, pekiştirme anlamı taşıyan fiiller türetir. Azerbaycan Türkçesinde birkaç kelime türetmiş̧ir: bükdele- "büküvermek", çözdele"çözüvermek", tepdele- "tepelemek" (Hac1eminoğlu, 1992, s. 136):

bükdele- "ağır yük taşıyan hayvan, yükü taşıyamayarak sendeleyerek yürümek" (DS, s. 816).

büzdelek "buruşuk" (DS, s. 833).

kıstala- "daraltmak, bunaltmak" (DS, s. 2844), gisdala- "sıkıştırmak; dara, zora sokmak, 1srar etmek" (EYSV, s. 89). krş. TTA ġısda- "sıkıştırmak" (AKD, s. 392).

kurdala- "karıştırmak, dokunmak, yoklamak" (DS, s. 3006).

sektele- "sıçrayarak yürümek" (DS, s. 3573).

yikdele- "oynarken topalliyormuş gibi hareket etmek" (KMİA, s. 542). TTA yek- "hafifçe topallamak" (DS, s. 4230).

2.2.21. -gIIA- / -gUIA-: Tarihî lehçelerden Çağatay Türkçesinde görülen ekin günümüzde Kuzey grubu Türk lehçelerinde ve Türkmen Türkçesinde örnekleri tespit edilmiştir (Räsänen, 1957, s. 165; Eckmann, 2009, s. 59; Hanser, 2003, s. 164; Arıkoğlu, 1996, s. 62; Güngördü, 1998, s. 179; Alkaya, 2008, s. 236; Uygur, 2010, s. 112). Altay Türkçesinde hemen her fiile eklenebilen işlek bir ektir (Güner Dilek, 2004, s. 787). Sıklık işlevine sahiptir: 
avklla- "örselemek, hırpalamak; ovmak, ovalamak" (DS, s. 385). TTA avkala- aa. (DS, s. 385), ovkala- "ufaklamak" (DS, s. 3299).

çalgıla- "tohumun toprağa karışması için toprağın üstünde bir dal parçası dolaştırmak" (DS, s. 1051).

gavırg̈la- "hafif kavurmak" (MAS, s. 168).

gergile- "germek" (DS, s. 2001).

örgüle- "örmek, onarmak" (DS, s. 4626).

sürgüle- "çekmek, sürüklemek” (DS, s. 3720).

yayğıla- "içinde az bir yiyecek olan kabı su ile çalkalamak" (DGBA, s. 482).

\subsection{Sadece TTA’da Görülen Yapım Ekleri}

Sadece TTA'da görülen eklerin büyük bir kısmı benzeşme sonucu ortaya çıkmış olan ekler ile birleşik eklerdir. Detaylı bir araştırma, bu eklerin bir kısmının tarihî ve çağdaş lehçelerde de bulunduğunu ortaya çıkarabilir.

2.3.1.+AdAn: Yansıma kökler üzerine gelen ek, zarf görevinde kelimeler türetir ve herhangi bir hareketin, olayın ansızın yapıldığını anlatır. + dAfiil yapma eki ile -n isim yapma ekinden oluşmuş birleşik bir ektir (Zülfikar, 1995, s. 144; Tietze, 2002, s. 484; Çotuksöken, 2011, s. 43). +AdAk eki ile aynı işlevi taşımaktadır:

cayıradan "birdenbire, şiddetli, çarçabuk" (DS, s. 869).

cızıradan "ince ve tiz sesle konuşma" (DS, s. 950).

firıdan "birdenbire, aniden yapılan bir hareketi anlatır" (DS, s. 1855).

gürpeden "birdenbire, ansızın" (DS, s. 2237).

hışadan "birden ve sert bir hışırtı ile" (DS, s. 2376).

kirpeden "birdenbire" (DS, s. 2881).

partadan "birdenbire, ansızın" (DS, s. 3401).

şaradan "şar sesi çıkararak (akmak için)” (DS, s. 3748).

şipirden "çarçabuk" (DS, s. 3771)

tıpadan "tıpatıp (uyma için)" (DS, s. 3917).

zırpadan "birdenbire" (AOA, s. 497).

2.3.2. +CAlIk: +CA eki ile +llk ekinin birleşmesinden oluşmuş bu ek, daha çok araç, giyecek ve yiyecek adları yapar. Aynı göreve sahip iki ekin üst üste gelmesi +CA ekinin tahsis işlevinin zayıflamış olduğunu göstermektedir (Aksoy, 1945, s. 206; Korkmaz, 1959, s. 332; Yedekçioğlu, 1992, s. 40): 
allahcaltg "sadaka" (HAİ, s. 34).

armançalıh "harman zamanı harmanlardan toplanan sadaka" (DS, s. 2292).

barmakçalık "çıta, düzgün biçilmiş ince uzun tahta" (DS, s. 534).

bayramçalık/ bayramcılık/ bayramşalık "bayram elbisesi” (DS, s. 584).

buruncallk "burunsalık" (DS, s. 803).

burunçalık "geniş yapraklı ve gri renkli bir yemlik türü" (NYA, s. 245).

çobancalık "sürüden herhangi bir koyun satıldığında alıcı tarafından çobana verilen bahşiş" (DS, s. 1253).

dişcelik "bebeğin dişi çıtığında bulgurdan bir yemek yapılması ve eş dostun bebeğe hediyeler getirmesine verilen ad" (ÇA, s. 521).

dogunçalıh "doğumu yaptıran köy ebelerine verilen hediye; davar, sığır yavruladığı zaman çobana verilen bahşiş" (DS, s. 1535), doğumcalıh "ebeye verilen hediye" (GKA, s. 467).

düğüncelik "düğün yapanlara komşular tarafından yapılan düğün yardımı" (DS, s. 1625).

ebecelik "doğumda ebeye verilen armağan ya da bahşiş" (DS, s. 1652).

emmicelik "bir kız evlenirken güveyin babası tarafından kızın amcalarına verilen para ya da herhangi bir eşya" (DS, s. 1741).

ergencelik "dul bir kadının genç bir erkekle evlendiği zaman kocasına verdiği armağan, tazminat" (DS, s. 1768).

ergençelik "evlenmemiş kız ya da erkeğin yüzünde ve boynunda çıkan sivilceler" (DS, s. 1768).

gatarcalıg "bir deveyi diğer deveye bağlayan ip" (ADÜM-I, s. 172).

golcalıh "kola takılan kolluk" (ADÜM-I, s. 175).

gö̈̈scelik "göğse takılan süs eşyası" (BTKA, s. 168).

ilmekçelik "çengelli iğne" (DS, s. 2533).

kapçalık "raf, sergen" (DS, s. 2631).

kurtçalık "çoban köpeğinin boynuna takılan mahmuzlu demir halka" (DS, s. 4572).

püşmancalıh "söz verip de pişman olduktan sonra ödenmesi gereken para ya da başka bir şey" (GKA, s. 564).

şirincelik "nişan için yapılan şerbet töreni" (DS, s. 3784).

tatlicalık "helva; lokum" (DS, s. 4742). 
2.3.3. +dIm / +dUm: Yansıma gövdelerin üzerine gelir. Genişletme ve pekiştirme işlevi taşımaktadır:

clğıldım "kuru gürültücü, geveze" (DS, s. 901).

cumbuldum "büyük, derin dere" (DS, s. 1015).

çiğirdim "filiz, taze yaprak" (DS, s. 1208).

çipildim "sulu çamur, su birikintisi” (DS, s. 955), çıpıldum "derinliği birkaç santimetreyi geçmeyen su birikintileri” (DS, s. 1183).

hışırdım "ağır; dalların eğilecek kadar meyve ile dolu oluşu" (DS, s. 2378). TTA hış "ağır; çok" (DS, s. 2375), hışır "bol" (DS, s. 2378).

kütürdüm "çalg1l1, her şeyi tamam (düğün)" (HKTS, s. 197).

şapırdım "hızlı, iri iri yağan yağmur" (DS, s. 3743), şapurdum "iri taneli yağmur” (DS, s. 3748).

şıkırdım "hızlı yağmur" (DS, s. 3766).

zığırdım "esintiyle savrularak yağan karla karışık yağmur, çıvgın" (DS, s. 4366). TTA zı̆̆ır zı̆̆ır "taneler ya da damlalar durumunda sürekli ve ses çıkararak yağmak, dökülmek için” (DS, s. 4366).

2.3.4 +DIrmA/ +DUrmA: Sadece birkaç kelimede tespit ettiğimiz bu ek, +DIrlk eki ile karşılaştıılabilir. +DIr- ile -mA eklerinin birleşmesinden meydana gelmiş olması ihtimal dâhilindedir:

çiğindirme "omuzla getirilen uzun odun" (DS, s. 1207). krş. TTA çiğindirik "su taşıyanların kullandıkları omuzluk" (DS, s. 1208).

şiptirme "hoppa, oynak kadın" (DS, s. 4728). krş. TTA şipdirim aa. (DS, s. 4728), şiftirik "gereksiz konuşan, geveze" (DS, s. 3776).

şişdirme/ şüş̧ürme "sacın üzerinde iyice kızartılıp şişe sarılarak rulo haline getirilmiş gevrek yufka ekmek" (MAS, s. 345).

şoldurma "su akan yer, su toplanan yer" (KASV, s. 250). krş. TTA çol "lavabo, banyo" (DS, s. 1262)?

2.3.5. +mAldAk: Yakınlık, benzerlik ifade eder, işlek değildir. Benzerlik ifade eden $+m A l$ ile küçültme eki $+d A k$ 'ın birleşmesinden oluştuğu düşünülebilir:

akmaltak "beyaza yakın" (DS, s. 159).

bezmeldek"1 "bir çeşit av kuşu" (DS, s. 653), mezmeldek/mezmendek/mezmeltek "yaban ördeği” (DS, s. 3176). krş. TTA mezgeldek “yaban ördeği” (DS, s. 3176), mezğeldek "yaban tavuğu" (DS, s. 4593), krş. Doğu Türkçesi biz

11 Lehçelerdeki şekiller için bk. (Eren, 1981, s. 7-8). 
tumşuq "gövdesi bir çeşit yabani ördeğinkine benzeyen, uzun bacaklı ve ibiği kırmızımsı tüylü bir kuş, kül rengine çalan sarı renktedir" (Ross, 1994, s. 14), TTA bizkuyruk "siyah başl1, sivri, uzun kuyruklu bir yaban ördeği" (DS, s. 714).

döşmeldek "orta boylu ve göbekli kimse" (DS, s. 1591).

şişmeldek "ham incir; şişmiş" (DS, s. 3788).

müzmeldek "çalı türünden olan gıcır ağacının yemişi”" (DS, s. 3231)?

2.3.6. +mAt: TTA' da nadir görülen bu ek, küçültme işlevine sahip olan + mAk ekinin bir varyantı olabilir:

hosmat "geçimsiz, huysuz" (DS, s. 2415). krş. TTA hoshos "yüzü gülmeyen, somurtkan (kimse)" (DS, s. 2415).

gıtmat "kıtça, az, azıcık" (UİA, s. 379). krş. TTA gıtsat aa. (UİA, s. 379).

gölbet "küçük su birikintisi, gölcük" (DS, s. 2141). krş. TTA gölek/ gölbeç/ gölbek/göleç/gölen/gölmeç aa. (DS, s. 2141).

ilikment "koyun ve kuzuların kuyruklarının dibindeki sert kısım" (DS, s. 2525). $<\mathrm{il}-\mathrm{ik}+\mathrm{me}(\mathrm{n}) \mathrm{t}$ ?

sekmet "basamak" (HA, s. 255). TTA sek/ seki "toprak üstündeki yükseklik, doğal set" (DS, s. 3568).

2.3.7. +mIr / +mUr: Çoğunlukla benzerlik ilgisi kuran ve eklendiği kelimeye olumsuz anlam katan nadir bir ektir. + mAr eki ile ilişkili olduğu düşünülebilir:

büsmürük “eski, yırtık elbiseli kimse” (DS, s. 830). krş. TTA büs "küspe; tutkal" (DS, s. 830).

cıhmır "sadece, arı, yalnız" (DS, s. 1168). krş. ET çak "doğru olarak, tamamıyla, tam" (ETG, s. 271, EUTS, s. 39), TTT çak/ çık "tam, tamam; sırf, salt, sade, yalnız, safi, halis" (YTS, s. 49).

hötmür "sabırsız ve kendi bildiğini yapan" (DS, s. 2439). krş. TTA hatmul "hatır gönül dinlemeden konuşan" (DS, s. 2306); < hat / höt "yansıma" + mur?

kösemur "başağı kılçıısız bir çeşit beyaz buğday" (DS, s. 2971). krş. TTA köse buğday aa. (DS, s. 2971).

mızmır "hoşa gitmeyen (iş, eşya)" (DS, s. 3196).

tüspür "biçim" (DS, s. 4015). TTA tüs "renk" (DS, s. 4014); ET tüs "görünüş" (ETY, s. 872), OT tüs "renk" (KBİ, s. 481).

2.3.8. +mUş: Yapısı hakkında herhangi bir bilgiye sahip olmadığımız bu eki, + mAç ile karşılaştırabiliriz: 
hezmuş "hırıltı" (THA, s. 867).

hotmuş "oyunda yere dikilmiş bir cisim" (ADÜM-II, s. 147). krş. TTA hotak aa. (DS, s. 2418), hot "biçimi yuvarlak olan (taş için)" (DS, s. 2418), kotmak "kütük parçası" (DS, s. 2937).

kölümüş "köstebek" (DS, s. 2955). krş. Krgz. kelemiş "tarla faresi, sıçan" (KrgzS, s. 433); krş. TTA kalağu aa. (DS, s. 2608), geleni/ gelengi "tarla faresi" (DS, s. 1975).

kütmüş "küçük kütük" (MAS, s. 272). krş. TTA kütmek/ kütmük/ kütmeç "ağaç kökü, kütük" (DS, s. 3054).

totmuş "karpuzun küçüğü" (MAS, s. 365). krş. TTA tot "top; şişman" (DS, s. 3974).

2.3.9. +sAlIk: Yazı dilinde görülmeyen bu ek, çoğunlukla araç gereç adları türetir (Atalay, 1941, s. 237). Kocasavaş, ekin +sA-, -1 ve +lIk eklerinin birleşmesinden oluştuğunu iddia etmiş, Türkçede -11- > -1- değişiminin pek çok örneği olduğunu belirtmiştir (1998, s. 427):

alınsalık "başlı̆̆ın hayvanın alnına takılan parçası" (AMA, s. 295).

bağırsalık "çocuğun önünü kirletmemesi için takılan önlük" (DS, s. 479).

boksalı "hayvan pisliğini taşımaya yarayan kap" (DS, s. 732).

boyunsalık "hayvanın boyun altından geçen geme ve yulara takılı ip; boyun atkısi; hamut" (DS, s. 748).

burunsalık "yularda başlığın burun üstüne gelen parçası" (DS, s. 804).

demirselik "sabanda, saban demirinin takıldığı yer" (DS, s. 1418).

goğüselik "kadınların giydiği bir çeşit süslü giysi”" (MTA, s. 197).

götselik "at, eşek, katır gibi hayvanların semerinin ardına ya da kalçasının üstüne gelen dokuma ipten yapılan saçaklı örtü” (MKS, s. 86).

günselik "bir şeye başlanacak gün, belli bir gün" (DS, s. 2230), günsalık “düğün için kararlaştırılan tarih" (DS, s. 2230).

kapısalık "çitten ya da aralıklı çakılan tahtalardan yapılmış bahçe kapısı" (DS, s. 2635).

önselik “iş önlüğü” (DS, s. 3342).

2.3.10. -AlAç: -AlAk eki ile benzer bir işlev taşımaktadır. İşlek değildir. Çoğunlukla alet adları türetir:

batalaç "sazlık, bataklık, çayırlarda kapalı küçük bataklık" (DS, s. 568).

dutalaç "tencere tutacağı" (DS, s. 1610). 
güdeleç “direksiyon, dümen” (MKS, s. 88), güdüleç “dümen, direksiyon; odun parçası, kısa ve kalın sopa" (DS, s. 2214).

sapalaç "aptal, sersem; anlamsız, saçma konuşan" (DS, s. 3539).

sürteleç "rende" (DS, s. 3722), sürteleş "keman yayı" (ADÜM-I, s. 203).

yatalaç "yatalak" (DRTA, s. 406, DTAS, s. 273).

2.3.11. -ArgI: -Ar sıfat-fiil eki ile +gI ekinin birleşmesinden oluşan bu ek, nadir görülür (Atalay, 1941, s. 117):

gezergi “çingene; seyyah" (DS, s. 2022, DİAT, s. 254).

gezargi "grip vb. bulaşıcı hastalıklar" (DS, s. 2019).

gidergi "gelip geçen, oturmayan, yolcu" (DS, s. 2074).

göçergi "tarlayı biçerken ya da sürerken aynı yönde ilerleyen işçi” (DS, s. 2121).

yürürkü "çağın, dünyanın gidiş̧i” (DS, s. 4334).

2.3.12. -nAl: Fiilden sifat türeten bir ektir (Tietze, 2002, s. 578; TS-VII, s. 237). Dönüşlü çatı eki -n- ile -Al fiilden isim yapma ekinin birleşip kaynaşması ile oluştuğu anlaşılmaktadır:

döğnel "toplu olarak bulunan şeylerin en iyi ve kalınları" (DS, s. 1571), TTA döynel "orta kalınlıkta, kalınca" (DS, s. 1594); krş. TTA döygel "dayanıkli; işe yarar", döy- "sabretmek, tahammül etmek, dayanmak" (DS, s. 1593); OT töz- "dayanmak, katlanmak" (KTS, s. 283).

döknel "oturakl1, ağırca; gösterişli" (DS, s. 1574).

ötnel "verimli, bitek" (DS, s. 3358). krş. TTA ötek "sürekli su çıkan yer", ötgün "su kaynağı" (DS, s. 3357).

öynel "ilkbaharda yerden kaynayıp bir süre sonra kaybolan su" (DS, s. 3364). krş. TTA öyek aa. (DS, s. 3364), öy- "yayılmak, içine geçmek" (DS, s. 3366), öğ- "emmek (toprağın su emmesi için)" (DS, s. 3316).

2.3.13. +DIr- / +DUr-: Nadir görülen bu ek, -DIr- fiilden fiil yapma ekinden örnekseme ile ortaya çıkmış olabilir. Çoğunlukla yansıma köklere eklenmektedir: $^{12}$

cızdır- "yağ kızdırmak" (DS, s. 947). TTA cızdırma "saçta veya tavada yapılan börek, ekmek" (DS, s. 947), cısdırma "sacda 1sıttılmış yağlı yufka" (DS, s. 941).

12 Ş. Tekin (1992), ET yiltir- / yiltri- "rüzgâr esmek" ve yaltır- / yaltrl- "parlamak" fiillerinde +1A- eki ile aşağı yukarı aynı anlamı taşıyan +DIr- ekinin olduğunu iddia etmiştir (s. 83). T. Tekin de (2004) yeltir- fiilinin +DIr- eki ile türemiş olabileceğini ifade etmiştir (s. 439). 
hoptur- "arkaya, sirta almak" (DS, s. 2405). krş. TTA hoput-/ hop et- aa. (DS, s. 2405).

huydur- "saldırmak, tepelemek" (UA, s. 205).

kıştır- " "kış’ diye kovmak” (BTA, s. 392).

sindiril- "sine gömülmek" (DS, s. 3638).

yeydir- "daha iyi olmak" (DS, s. 4259).

2.3.14. +(I)ksA- / +(U)ksA-: Yakınlık, benzerlik anlamı taşıyan bu ek, nadir görülür. Fiilden fiil yapan -(I)ksA- ekinden örnekseme ile veya +(I)k- ile -sA- eklerinin birleşmesi ile oluşmuştur:

azıksa-/ azıksan- "az görmek, az bulmak" (HKTS, s. 18; AKGA, s. 31).

gecikse- "biraz geç kalmak" (DS, s. 1959).

otuksa- "hayvan yavrusu ot yemeye başlamak" (DS, s. 4616). krş. TTA otuk- aa. (DS, s. 3295).

2.3.15. -AnlA-: Sıklık ifade eden bu ekin yapısı açık değildir. Çoğunlukla aynı kelimelerin -AlA- ile kurulu şekilleri de olduğundan /n/ türeme bir ses izlenimi vermektedir. Ek, -An sıfat-fiil eki ile +lA- ekinin birleşmesinden de oluşmuş olabilir. Çoğunlukla Abdal gruplarının yaşadığ 1 yerlerde görülmektedir (Yıldırım, 2008, s. 65). Ekin benzeşme ile oluşan -AnnA- biçimi daha yaygindir:

atanna- "atmak, firlatmak" (TD, s. 58).

azanna- "yara, çıban azmak" (DS, s. 435), azayna- "yara, çıban büyümek azmak; kavga kızışmak, büyümek" (DS, s. 4436).

bahanna- "bakmak" (TD, s. 58).

çekenle- "sağından solundan çekmek" (EAFS, s. 36).

dolanna- "dolamak, sarmak; dolandirmak" (TD, s. 59).

duranna- "durmak" (TD, s. 59).

gaçanna- "kaçmak" (TD, s. 59).

gezenne- "gezelemek" (MA, s. 299).

kakanla- "itelemek, sarsmak, sokuşturmak" (DS, s. 2601).

ölenne- "ölmek" (TD, s. 62).

savanna- "iki kişi gizli konuşmak için yanlarında bulunan üçüncü kişiyi başlarından savmak" (DS, s. 3553).

şaşanla- "şaşırmak" (SYA, s. 746).

yakanna- "yakmak, ateşe vermek" (TD, s. 63). 
2.3.16. -AtlA-: Sıklık bildiren birleşik bir ektir:

düzetle- "düzeltmek" (KMİA, s. 348).

evetle- "acele etmek, acele ettirmek" (DS, s. 1811), avatla-/ivetle- "acele etmek" (DS, s. 378, 2572), övetle- "ivmek" (DS, s. 3362), yivetle- "bir işin yapılması için sıkıştırmak, dürtüklemek" (DS, s. 4283). TTA ev- "acele etmek" (DS, s. 1811); ET eb- "acele etmek" (OTG, s. 242).

gavuratla- "kavurmak" (DlmA, s. 160).

gırıtla- "kırmak, ufak parçalara ayırmak" (ZBKA, s. 186).

goşatla- "halı ve kilim dokuma için 1stara çözgü etmek" (DGBA, s. 471). kısatla- "sıkıştırmak" (DS, s. 2840).

övetle- "ezip ovarak, iki şeyi birbirine sürterek ufalamak, mısır koçanlarını tanelemek" (DS, s. 3362).

\section{Sonuç}

Zengin bir yapım eki varlığına ve türetme gücüne sahip olan TTA'da, yazı dilinde bulunmayan pek çok yapım eki vardır. Yazı dilinde bulunmayan bu yapım eklerinden bir kısmı tarihî ve çağdaş lehçelerde de görülürken bir kısmı sadece TTA'da yer almaktadır. Sadece TTA'da görülen eklerin önemli bir kısmı benzeşme sonucu ortaya çıkan ekler ile birleşik yapıdaki eklerdir. Yazı dilinde bulunmayan eklerin büyük bir kısmının isimden isim yapan ekler olması dikkat çekmektedir.

TTA'da, yazı dilinde unutulmuş olup da Tarihî ve çağdaş lehçelerde kullanılan eklerin bulunması ve bu eklerle pek çok kelimenin türetilmiş olması Türk dili araştırmaları için büyük bir kazançtır. Bu ekler ile kurulu kelimeler, Türk dili tarihindeki bazı sorunların çözümüne katkı sağlayacaktır. Aynı zamanda yazı dilinde olmayan bu eklerin işletilmesi, bu eklerle kurulu kelimelerden uygun olanların yazı diline kazandırılması, Türkçenin gücüne güç katacaktır.

\section{Taranan Eserler ve Kisaltmaları}

AA: Aksoy, Ö. A. (1946). Gaziantep A ̆ğz III. İstanbul: İbrahim Horoz.

AAS: Uyguç, A. A. (2006). Aydın Ă̆zı ve Sözlüğü. Aydın: Kolalı.

ADÜM-I: Caferoğlu, A. (1994). Anadolu Dialektolojisi Üzerine Malzeme I. Ankara: Türk Dil Kurumu.

ADÜM-II: Caferoğlu, A. (1994). Anadolu Dialektolojisi Üzerine Malzeme II. Ankara: Türk Dil Kurumu.

AKD: Olcay, S., Ercilasun, A. B., Aslan, E. (1998). Arpaçay Köylerinden Derlemeler. Ankara: Türk Dil Kurumu. 
AKGA: Cin, A. (2011)."Arıkuyusu/ Kuşak (Gülnar) Ağzı". Mediterranean Journal of Humanities, I/2, 21-46.

AMA: Boz, E. (2006). Afyonkarahisar Merkez Ăgzı. Ankara: Gazi.

AOA: Yıldırım, F. (2006). Adana ve Osmaniye Ağızları. Ankara: Türk Dil Kurumu.

AYA: Doğan, M. (2012). Aksaray ve Yöresi Ağızları. (Yayımlanmamış doktora tezi). Erciyes Üniversitesi, Kayseri.

AybA: Aydın, M. (2002). Aybastı Ağzl. Ankara: Türk Dil Kurumu.

BKHK: Yıldırım, A. (2004).”Berendi Köyü Hayvan ve Hayvancılıkla İlgili Kelimeler". TDAY-Belleten 2002, 95-105.

BnİA: Dülger, E. (2007). Banaz İlçesi Ă̆zı. (Yayımlanmamış yüksek lisans tezi). Gazi Üniversitesi, Ankara.

BTA: Mollova, M. R. (1974).”Balkanlarda Türk e- Ağızları”. Güneydoğu Avrupa Araştırmalart Dergisi, 2-3, 357-414.

BTKA: Göker, O. (1996). Bolvadin'deki Türkmen-Karabă̆ Köylerinin Ağzı. (Yayımlanmamış yüksek lisans tezi). Afyon Kocatepe Üniversitesi, Afyonkarahisar.

BYA: Kibar, O. (1998). Biga Yöresi Ağızları. (Yayımlanmamış yüksek lisans tezi). Çanakkale On Sekiz Mart Üniversitesi, Çanakkale.

ÇA: Şimşek Umaç, Z. (2011). Çepni Ağzı. (Yayımlanmamış doktora tezi). Balıkesir Üniversitesi, Balıkesir.

ÇADK: Tokat, F. (2014).”Çavdır Ağzından Derleme Sözlüğü’ne Katkılar”. Uluslararası TEKE Dergisi, 3(1), 153-166.

DADK: Dağdaş, S., Dağdaş, F. B. (2005).”Denizli-Acıpayam Dodurgalar Kasabasından Derlenen Kelimelerimiz". TDAY-Belleten 2005, 7-55.

DGBA: Tok, Turgut (2002). Denizli Illi Güney ve Güneybatı Bölgesi Ağızları. (Yayımlanmamış doktora tezi). Pamukkale Üniversitesi Sosyal Bilimler Enstitüsü, Denizli.

DİAS: Uygur, C. V. (2007). Denizli İli Ağız Sözlüğü. Isparta: Fakülte.

DİAT: Caferoğlu, A. (1995). Doğu illerimiz Ağızlarından Toplamalar. Ankara: Türk Dil Kurumu.

DlmA: Karadağ, S. (2001). Dalaman Ăgzı. (Yayımlanmamış yüksek lisans tezi). Muğla Üniversitesi, Muğla.

DRTA: Mollova, M. R. (2003). Doğu Rodop Türk Ağızlarının Sözlüğü. Ankara: Türk Dil Kurumu.

DS: Türk Dil Kurumu (1963-1982). Derleme Sözlüğ̈̈ I-XII. Ankara: Türk Dil Kurumu.

DSİ: Koraş, H. (2002).”Derleme Sözlügü̈’ne İlaveler”. TÜBAR, 12, 171-208.

DTAS: Cebeci, İ. (2010). Örneklerle Deliorman Türk Ağzı Sözlüğ̈̈. Ankara: Türk Dil Kurumu.

EİA: Gemalmaz, E. (1995). Erzurum İli Ağlzları III (Bibliyografya, Sözlük ve Dizinler). Ankara: Türk Dil Kurumu.

EYDS: Erdoğan, M. (2008). Ereğli Yöresinden Derlemeler Sözlüğü. İzmir: İlya Yayınevi.

EYSV: Buran, A., İlhan, N. (2008). Elazığ Yöresi Söz Varlı̆̆ı. Ankara: Türk Dil Kurumu.

GDIA: Erkap, S. (1999). Gül Dili Isparta Ağzı. Ankara: Mina.

GKA: San, S. Ö. (1990). Gümüşhane Kültür Araştırmaları ve Yöre Ağızları. Ankara: Kültür Bakanlığı. 
GpKA: Küçükballı, F. N. (2013). Gazipaşa (Antalya) Köyleri Ağzı. (Yayımlanmamış yüksek lisans tezi). Selçuk Üniversitesi, Konya.

HA: Alan, M. (2012). Hacılar A ğzı. (Yayımlanmamış yüksek lisans tezi). Erciyes Üniversitesi, Kayseri.

HAİ: Haşimi, A. (2001). Hassa A ğzı İncelemesi. (Yayımlanmamış yüksek lisans tezi). Yüzüncü Y1l Üniversitesi, Van.

HKTS: Hakeri, H. B. (2003). Hakeri'nin Kıbrıs Türkçesi Sözlüğü. Gazimağusa: Samtay Vakfi.

HrpA: Güler, Z. (1992). Harput Ağzı. Elazı̆̆g: Elazığ Belediyesi.

KA: Yedekçioğlu, K. (1992). Kayseri Ă̆zı II-Sözcükler. Kayseri: Beğendik.

KABK: Yıldırım, A., Yıldırım, Ü. (2015).’Karaman/Ayrancı Berendi Köyünde Kullanılan Orijinal Fiiller". 7. UDDTS (16-18 Ekim 2014, Elazığ) içinde (s. 699-710). Elazığ: Firat Üniversitesi.

KASV: Özkaya, H. (2013). Kırklareli İli A ğızları Söz Varlı̆̆ı. (Yayımlanmamış yüksek lisans tezi). Trakya Üniversitesi, Edirne.

KBLG: Batkan, N. A. (2000). Kıbrıs Baf ve Limasol Türk Göçmenlerinin Ağzı. (Yayımlanmamış yüksek lisans tezi). Gazi Üniversitesi, Ankara.

KbrA: Saracoğlu E. (2004). Kıbrıs Ă̆zz. Lefkoşa: Ateş Matbaacılık.

KİA: Uysal, İ. N. (2009). Karaman İli Ağızları ve Anadolu Ă̆ızları Arasındaki Yeri. (Yayımlanmamış doktora tezi). Pamukkale Üniversitesi, Denizli.

KkA: Yavuz, S. (2003). Karakeçili Ă̆zı (Kırıkkale). (Yayımlanmamış yüksek lisans tezi). Frrat Üniversitesi, Elazı̆̆.

KMİA: Bayraktar, F. S. (2000). Kayseri Merkez İlçe Ağzı. (Yayımlanmamış doktora tezi). Trakya Üniversitesi, Edirne.

KmYA: Tekin, F. (1994). Kaman ve Yöresi Ă̆ızları. (Yayımlanmamış yüksek lisans tezi). Erciyes Üniversitesi, Kayseri.

KsYA: Acar, E. (2012). Kastamonu ve Yöresi Ağızları. (Yayımlanmamış doktora tezi). Trakya Üniversitesi, Edirne.

KYA: Gülensoy, T. (1988). Kütahya ve Yöresi Ağızları. Ankara: Türk Dil Kurumu.

KYAS: Günşen, A. (2001). Kırş̧ehir ve Yöresi A ğızları Sözlü̆̆̈̈. Ankara: Ocak.

MA: Akar, A. (2004). Muğla Ă̆ızları. Muğla: Muğla Üniversitesi.

MAS: Tor, G. (2004). Mersin A ğzı Sözlüğ̈̈. İstanbul: Kebikeç.

MİA: Gülseren, C. (2000). Malatya İli Ağızları. Ankara: Türk Dil Kurumu.

MİAS: Çınar, A. A. (2004). Muğla İli Ă̆zı Sözlüğü. İzmir: Birleşik.

MKS: Kaya, Ö., Kozan, H. A. (2003). Mahalli Kelimeler Sözlüğü. Kahramanmaraş: Ukde.

MTA: Kandemir, S. (2006). Manyas Türkmen Ă̆zı. (Yayımlanmamış yüksek lisans tezi). Çanakkale On Sekiz Mart Üniversitesi, Çanakkale.

NYA: Aksu, A. (2013). Nurhak ve Yöresi Ă̆zı. (Yayımlanmamış yüksek lisans tezi). Erciyes Üniversitesi, Kayseri.

OAAD: Caferoğlu, A. (1994). Orta Anadolu Ağızlarından Derlemeler. Ankara: Türk Dil Kurumu.

OGE: Durmaz, R. (2009).”Oğuzcadan Gelen Esinti: Karakoyunlu Yörükleri Ağzından Büyük Türkçe Sözlüğe Katkılar". Turkish Studies, 4/4, 331-466. 
PTK: Yapıcı, S. (2004). Palu Tarih-Kültür-İdari ve Siyasi Yapı. Elazığ: Anıl.

SiYA: Demir, N., Şen, Ü. (2006). Sivas İli ve Yöresi Ağızları. Ankara: Gazi.

SMA: Özçelik, S., Boz, E. (2009). Siverek Merkez Ă̆zl. Ankara: Gazi.

SMYA: Öztürk, E. (2009). Silifke ve Mut’taki Sarıkeçili ve Bahşiş Yörükleri Ağzı. Ankara: Türk Dil Kurumu.

STİA: Caferoğlu, A. (1994). Sivas ve Tokat İlleri Ağızlarından Toplamalar. Ankara: Türk Dil Kurumu.

SYA: Demir, İ. (2012). Sarıgöl ve Yöresi Ă̆ızları. (Yayımlanmamış doktora tezi). Erciyes Üniversitesi, Kayseri.

TD: Yıldırım, F. (2008).’Teber Dili”. Kültür Tarihimizde Gizli Diller ve Şifreler içinde (s. 52-74). E. G. Naskali, E. Şahin (ed.). İstanbul: Picus.

THA: Kuyumcu, O. (2006). Türkçenin Hemşin Ă̆zl. (Yayımlanmamış yüksek lisans tezi). Marmara Üniversitesi, İstanbul.

TiYYA: Demir, N. (2006). Tokat İli ve Yöresi Ağızları. Ankara: Gazi.

TKYA: Akçam, M. (1999). Torul ve Kelkit Yöresi Ağızları. (Yayımlanmamış yüksek lisans tezi). Gazi Üniversitesi, Ankara.

UA: Gülbahar, B. (2010). Uluborlu Ağzı. (Yayımlanmamış yüksek lisans tezi). Süleyman Demirel Üniversitesi, Isparta.

UİA: Gülsevin, G. (2002). Uşsak İli Ağızları. Ankara: Türk Dil Kurumu.

VGHA: Gökçur, E. (2012). Van Gölü Havzası Ağızları. (Yayımlanmamış doktora tezi). Firat Üniversitesi, Elazığ.

YYA: Acer, F. (2003). Yerköy ve Yöresi Ağızları. (Yayımlanmamış yüksek lisans tezi). Erciyes Üniversitesi, Kayseri.

ZBKA: Eren, M. E. (1997). Zonguldak-Bartın-Karabük İlleri Ağızları. Ankara: Türk Dil Kurumu.

\section{Diğer Kısaltmalar}

aa.: aynı anlam

ADDL: Azərbaycan Dilininin Dialektoloji Lüğəti (Nəsimi adına Dilçilik İnstitutu, 2007).

Alt.: Altay Türkçesi

ATBS: Azerbaycan Türkçesi'nden Türkiye Türkçesi’ne Büyük Sözlük (Akdoğan, 1999).

Az.: Azerbaycan Türkçesi

Çağ.: Çağatay Türkçesi

DLTD: Divanü Lûgat-it-Türk Dizini (Atalay, 1986).

ET: Eski Türkçe

ETG: Eski Türkçenin Grameri (Gabain, 1988).

ETY: Eski Türk Yazıtlarl (Orkun, 1994).

EUTS: Eski Uygur Türkçesi Sözlüğü (Caferoğlu, 1993).

Hak.: Hakas Türkçesi

KBİ: Kutagu Bilig III Indeks (Arat, 1979).

Krgz.: Kırgız Türkçesi

KrgzS: Kırgız Sözlüğ̈̈ (Yudahin, 1988). 
KTS: Kıpçak Türkçesi Sözlüğ̈̈ (Toparlı vd., 2007).

LÇ: Luġat-i Çaġatay ve Türkî-yi Osmanî (Şeyh Süleyman Efendi-yi Buhârî, 1298).

OT: Orta Türkçe.

OTG: Orhon Türkçesi Grameri (Tekin, 2003).

Özb.: Özbek Türkçesi

TAS: Teleüt Ăgzı Sözlüğü (Sırkaşeva ve Kuçigaşeva, 2000).

TS-VII: Tarama Sözlüğü VII Ekler (TDK, 1996).

TTA: Türkiye Türkçesi Ağızları

TTT: Tarihî Türkiye Türkçesi

Tuv.: Tuva Türkçesi

YTS: Yeni Tarama Sözlüğü (TDK, 1983).

YUTS: Yeni Uygur Türkçesi Sözlüğü (Necip, 1995).

YUyg.: Yeni Uygur Türkçesi

\section{Kaynaklar}

Akdoğan, Y. (1999). Azerbaycan Türkçesi’nden Türkiye Türkçesi’ne Büyük Sözlük. İstanbul: Beşir.

Aksoy, Ö. A. (1945). Gaziantep A ğzı I (Gramer). İstanbul: İbrahim Horoz.

Alkaya, E. (2008). Sibirya Tatar Türkçesi. Ankara: Turkish Studies. (2014a). Mişer Tatar Türkçesi, İstanbul: Kesit.

(2014b)."Signs of The Old Turkic Language in Tatar Dialects: Suffix-Dachy Functioning". Jurnal Tatarica / Vipusk, 2, 37-48.

Arat, R. R. (1979). Kutagu Bilig III İndeks. K. Eraslan, O. F. Sertkaya ve N. Yüce (haz.). İstanbul: TKAE.

Arıkoğlu, E. (1996). Tuva ve Hakas Türkçelerinde Fiil. (Yayımlanmamış doktora tezi). Gazi Üniversitesi, Ankara.

(2007).’Tuva Türkçesi”. Türk Lehçeleri Grameri içinde (s. 1149-1228). A. B. Ercilasun (ed.). Ankara: Akçăg.

Atalay, B. (1941). Türk Dilinde Ekler ve Kökler Üzerine Bir Deneme. İstanbul: Türk Dil Kurumu.

(1986). Divanü Lûgat-it-Türk Dizini. Ankara: Türk Dil Kurumu.

Banguoğlu, T. (1988).’Türkçede Benzerlik Sıfatları”. TDAY-Belleten 1957, 13-27. (2004). Türkçenin Grameri. Ankara: Türk Dil Kurumu.

Bilgen, İ. (1989). Dîvānu Lug̀āti't Turk'te Söz Yapımı. (Yayımlanmamış doktora tezi). Hacettepe Üniversitesi, Ankara.

Biray, H. (1999). Batı Grubu Türk Yazı Dillerinde Ísim. Ankara: Türk Dil Kurumu.

Brockelmann, C. (1954). Osttürkische Grammatik der islamischen Litteratursprachen Mittelasiens. Leiden: E. J. Brill.

Caferoğlu, A. (1993). Eski Uygur Türkçesi Sözlü̆̆̈̈. İstanbul: Enderun.

Ceritoğlu, M. (1998). Kırgız Türkçesinin Şekil Bilgisi. (Yayımlanmamış doktora tezi). Çanakkale Onsekiz Mart Üniversitesi, Çanakkale. 
Clauson, G. (1972). An Etymological Dictionary of Pre-Thirteenth Century Turkish. Oxford: Oxford University.

(2007).”Türkçede Sekizinci Yüzyıldan Önce Kullanılan Ekler”. U. Özalan (çev.). Dil Araştırmaları, 1, 185-196.

Coşkun, V. (2000). Özbek Türkçesi Grameri. Ankara: Türk Dil Kurumu.

Çağatay, S. (1967).’Pekiştirilen Fiiller”. TDAY-Belleten 1966, 39-50.

Çeneli, İ. (1997). Kırım Tatarcasında Yapım Ekleri. Ankara: Türk Dil Kurumu.

Çotuksöken, Y. (2011). Türkiye Türkçesinin Ekleri. İstanbul: Papatya.

Deny, J. (1941). Türk Dili Grameri (Osmanlı Lehçesi). A. U. Elöve (çev.). İstanbul: Maarif Vekâleti.

Eckmann, J. (2009). Çağatayca El Kitabı. Günay Karaağaç (çev.). İstanbul: Kesit.

Eraslan, K. (1980). Eski Türkçede İsim-Fiiller. İstanbul: İÜ Edebiyat Fakültesi. (1996)."+si-/ +si- (+su-/ +sü-) İsimden Fiil Yapma Eki ile -s1- / -si- (-su-/ -sü-) Fiilden Fiil Yapma Eki ve Genişlemiș Șekilleri Hakkında”. TKAE, XXXII / 1-2 (Zeynep Korkmaz'a Armă̆an), 47-62.

Ercilasun, A. B. (2007).’Türkçede Benzerlik Bildiren +m Morfemi”. Dil Araştırmaları, 1, 9-20.

Erdal, M. (1991). Old Turkic Word Formation I-II. Wiesbaden: Otto Harrassowitz.

Eren, H. (1981).’Türk Dilinin Étymologique Sözlügüne Katk1lar”. TDAY-Belleten 19781979, 1-15.

(1999). Türk Dilinin Etimolojik Sözlüğü. Ankara: Bizim Büro.

Ergin, M. (1990). Türk Dil Bilgisi. Ankara: Bayrak.

Gabain, A. (1988). Eski Türkçenin Grameri. M. Akalın (çev.). Ankara: Türk Dil Kurumu.

Ganiyev, F. (2013). Bugünkü Tatar Türkçesi Söz Yapımı. M. Özşahin (çev.). Ankara: Türk Dil Kurumu.

Gülensoy, T. (2007). Türkiye Türkçesindeki Türkçe Sözcüklerin Köken Bilgisi Sözlüğü I (A$N)$ - II (O-Z). Ankara: Türk Dil Kurumu.

Gülsevin, G., Gülsevin, S. (1993). (Kamus-ı Türkiye Göre) Türkçede Yapım Ekleri ve Kullanılışları I: Fiilden İsim Yapan Ekler. Malatya.

(1997). Eski Anadolu Türkçesinde Ekler. Ankara: Türk Dil Kurumu.

Güner Dilek F. (2004).”Altay Türkçesindeki \{-GIlA-\} Eki Hakkında". V. UTDK içinde (s. 787-791). Ankara: Türk Dil Kurumu.

(2007).”Altay Türkçesi”. Türk Lehçeleri Grameri içinde (s. 1009-1084). A. B. Ercilasun (ed.). Ankara: Akçağ.

Güngördü, E. (1998). Kazak, Kırgız ve Karakalpak Türkçelerinde Fiil. (Yayımlanmamış doktora tezi). Gazi Üniversitesi, Ankara.

(2002).’'Isimden Fiil Türeten +ç1-/ +çi- Eki ve Gelişmiş Şekilleri”. Gazi Eğitim Fakültesi Dergisi, XXII, 3, 171-182.

(2009).”-çA- Eki ve Genişlemiş Şekilleri”. Leyla Karahan Armağanı içinde (s. 579-598). Ankara: Akçağ.

Güzel, F. (2015). Türkiye Türkçesi A ̈̆ızlarında Söz Yapımı. (Yayımlanmamış doktora tezi). Firat Üniversitesi, Elazığ.

Hacıeminoğlu, N. (1992). Türk Dilinde Yapı Bakımından Fiiller. Ankara: Kültür Bakanlığı. 
Hanser, O. (2003). Türkmence El Kitabı. Z. Karg1 Ölmez (çev.). İstanbul: Mehmet Ölmez. İlker, A. (1997). Batı Grubu Türk Yazı Dillerinde Fiil. Ankara: Türk Dil Kurumu.

Kaçalin, M. S., Bilgin A. A. (1997).”+lağu / +legü Eki Üzerine”. Türkiyat Mecmuası, XX, 69-84.

(2006). Dedem Korkut'un Kazan Bey Oğuz-nâmesi. İstanbul: Kitabevi.

Kara, M. (2001). Türkmence. Ankara: Akçağ.

Kara, M. (2005). Hakas Türkçesinde İsim. (Yayımlanmamış doktora tezi). Gazi Üniversitesi, Ankara.

Kartallığlu, Y., Yıldırım, H. (2007).”Azerbaycan Türkçesi”. Türk Lehçeleri Grameri içinde (s. 171-230). A. B. Ercilasun (ed.). Ankara: Akçağ.

Kasapoğlu Çengel, H. (2005). Kırgız Türkçesi Grameri. Ankara: Akçağ.

Kaymaz, Z. (2000).”Türkiye Türkçesi ve Ağızlarında Renk Bildiren Kelimelerin Kullanıl1Ş1 ve Sistematiği". TDAY-Belleten 1997, 251-341.

Kocasavaş, Y. (1998).”+sa- / +se- İsimden Fiil Yapma Eki ile -sa- / -se- Fiilden Fiil Yapma Eki ve Genişletilmiş Şekilleri”. TDED, XXVIII, 419-434.

Koraş, H. (1998). Özbek ve Uygur Türkçelerinde İsim. (Yayımlanmamış doktora tezi). Erciyes Üniversitesi, Kayseri.

Korkmaz, Z. (2003). Türkiye Türkçesi Grameri (Şekil Bilgisi). Ankara: Türk Dil Kurumu.

Mansuroğlu, M. (1956).’’ürkçede -taçı Ekinin Fonksiyonları”. TDED, 7, 1-2, 105-108.

Necip, E. N. (1995). Yeni Uygur Türkçesi Sözlüğü. İ. Kurban (çev.). Ankara: Türk Dil Kurumu.

Nəsimi adına Dilçilik İnstitutu (2007). Azərbaycan Dilininin Dialektoloji Lüğəti. Bakı: Şərq-Gərb.

Orkun, H. N. (1994). Eski Türk Yazıtları. Ankara: Türk Dil Kurumu.

Özel, S. (1977). Türkiye Türkçesinde Sözcük Türetme ve Birleştirme. Ankara: Türk Dil Kurumu.

Özkan, F. (2004).”-mak, -mek Eki İle Yapılan Kalıcı İsimler”. V. UTDK içinde (s. 22772282). Ankara: Türk Dil Kurumu.

Öztürk, R. (1997). Uygur ve Özbek Türkçelerinde Fiil. Ankara: Türk Dil Kurumu. (2015). Yeni Uygur Türkçesi Grameri. Ankara: Türk Dil Kurumu.

Räsänen, M. (1957). Materialien zur Morphlogie der türksichen Sprachen. Helsinki: Studia Orientalia Edidit Societas Orienatalis Fennica XXI.

(1969). Versuch eines etymologischen Wörterbuchs der Türksprachen. Helsinki: Lexsika Societatis Fenno-Ugricae XVII/ 1.

Ross, E. D. (1994). Kuş İsimlerinin Doğu Türkçesi, Mançuca ve Çince Sözlüğü. E. Gürsoy-Naskali (çev.). Ankara: Türk Dil Kurumu.

Serebrennikov, B. A., Gadjieva, N. Z. (2011). Türk Yazı Dillerinin Karşılaş̧ırmalı Tariĥ̂ Grameri. Tevfik Hacıyev ve Mustafa Öner (çev.). Ankara: Türk Dil Kurumu.

Sırkaşeva, L. T., Kuçigaşeva, N. A. (2000). Teleüt Ă̆zı Sözlüğü. Ş. H. Akalın ve Ç. Turgunbayev (çev.). Ankara: Türk Dil Kurumu.

Söyegow, M., Borjakov, A., Sarıhanov, M., Hocayev, B., Ärnazarov, S. (1999). Türkmen Diliniy Grammatikast-Morfologiya. Aşgabat: Ruh. 
Şeyh Süleyman Efendi-yi Buhârî (H 1298). Luġat-i Çaġatay ve Türkî-yi Osmanî. İstanbul: Mihran.

Türk Dil Kurumu (1983). Yeni Tarama Sözlüğü. C. Dilçin (haz.). Ankara: Türk Dil Kuru$\mathrm{mu}$.

Türk Dil Kurumu (1996). Tarama Sözlüğ̈̈ VII Ekler. Ankara: Türk Dil Kurumu.

Tabaklar, Ö. (1994). Türkmencenin Morfolojisi. (Yayımlanmamış doktora tezi). İstanbul Üniversitesi, İstanbul.

Taş, İ. (2009). Kutadgu Bilig'de Söz Yapımı. Ankara: Türk Dil Kurumu.

Tekin, Ş. (1992).’Eski Türkçe”. Türk Dünyası El Kitabı II içinde (s. 69-119), Ankara: TKAE.

Tekin, T. (2003a). Orhon Türkçesi Grameri. İstanbul: Simurg.

(2003b)."Zetacism and Sigmatizm in Proto-Turkic". Makaleler I - Altayistik içinde (s. 1-37). Ankara: Grafiker.

(2004).”Notes on Old Turkic Word Formation”. Makaleler II - Tarihi Türk Yazı Dilleri içinde (s. 414-447). Ankara: Öncü.

Tietze, A. (2002). Tarihî ve Etimolojik Türkiye Türkçesi Lugatı I (A-E). İstanbul-Wien: Simurg.

Toparlı, R., Vural, H., Karaatlı, R. (2007). Kıpçak Türkçesi Sözlüğü. Ankara: Türk Dil Kurumu.

Uygur, C. V. (1994). Kırgız, Kazak, Karakalpak Türkçelerinde İsim. (Yayımlanmamış doktora tezi). Gazi Üniversitesi, Ankara. (2010). Karakalpak Türkçesi Grameri. İstanbul: Kriter.

Uzun, N. E., Uzun, L. S., Aksan, Y. K., Aksan, M. (1992). Türkiye Türkçesinin Türetim Ekleri-Bir Döküm Denemesi. Ankara: Şirin.

Yedekçioğlu, K. (1992). Kayseri Ağzı II-Sözcükler. Kayseri: Beğendik.

Yıldırım, F. (2008).’Teber Dili”. Kültür Tarihimizde Gizli Diller ve Şifreler içinde (s. 5274). E. G. Naskali ve E. Şahin (ed.). İstanbul: Picus.

Yudahin, K. K. (1988). Kırgız Sözlüğü I-II. A. Taymas (çev.). Ankara: Türk Dil Kurumu.

Zülfikar, H. (1995). Türkçede Ses Yansımalı Kelimeler. Ankara: Türk Dil Kurumu. 


\section{Extended Abstract}

Turkey Turkish Dialects (TTA), is filled with many problems in the data shed light on the history of Turkish language. It is seen that many words and constructions in contemporary dialects are contained in TTA, with many words and construction suffixes in historical dialects, or similar forms in TTA.

96 books, 1 dissertation thesis, 18 doctoral dissertations, 178 master's theses, 53 articles and papers have been examined by us, and the dictionaries which have been examined in order to contribute to the Dictionary about 40,000 words from the dictionary and form information sections of the mouth works are marked. Since the main purpose is to collect the derived words that are not in the written language, to determine the appendices that are not in the written language and to determine the different functions of these inserts, the words which are found in the written language and the same or various sound events in the mouths are excluded from the scope of the examination.

In order to understand the structure of the words that were thought to be derived, etymological sources were examined, the works on foreign elements in Turkish, and dictionaries about historical and contemporary dialects were applied. The words which emerged with various sound events of the same word, the words merged with the original form, and the words that have been found to be completely foreign to the structure of any words can not be found. The remaining approximately 25,000 words derived based on the basis of the vocabulary adds construction seen in Turkey Turkish dialects were studied in detail.

In this study, after giving general information about the presence of derivational suffixes in TTA and the degree of activity of these suffixes, we will focus on 50 derivational suffixes which are not in written language, and will be given to some of the words derived from these suffixes. Of course, it can be argued whether a part of the elements here is a derivational suffixes, different opinions about the structure of some suffixes and words can be suggested. One of the aims of this study is to discuss the existence of the derivational suffixes in TTA.

It was determined that 10456 derived from nouns with name-making suffixes in TTA, derived from verbs with naming additions 7640 , derived from noun with verbal suffixes 4440 , derived from verb with suffixes 2417 , in 24953 derived from non-written language. This number, which shows the derived words not found in the written language in the works that we can only examine, clearly demonstrates the great treasure of TTA.

Most of the words in this study are permanent words. Non-persistent words have not been evaluated except for the words that are listed in order to de- 
monstrate the variants and different functions of the permanent non-deriving constructs. + gil, + eli, + o etc. inserts are commonly used in TTA. The material attached to such attachments is used to show different shapes and different functions, and not to the whole of the material that is attached to the tables showing the activity ratio of the suffixes.

In TTA, Approximately 140 suffixes have been determined that are not founded in Turkey Turkish written language. Although some construction suffixes which have derived various words in historical dialects have been forgotten in the written language, they maintain their presence in TTA. The fact that some of the construction suffixes in historical dialects are preserved in TTA is a great gain for Turkish language research. The words with these suffixes in TTA will contribute to the solution of some problems in the history of Turkish language. Some inserts, which are not seen in written language, have similar functions in contemporary dialects. It is noteworthy that some attachments in TTA are seen in distant dialects such as Hakas and Altay Turkish. Only a large part of the inserts seen in TTA are combined inserts with inserts that have emerged as a result of affinity. A detailed study may reveal that some of these suffixes are also found in historical and contemporary dialects.

TTA has a rich construction attachment and has the power of derivation. Some of these construction suffixes, which are not in written language, are also seen in historical and contemporary dialects and some of them are only in TTA. Only a significant part of the suffixes seen in TTA are the inserts that are combined with the appendages resulting from affinity. It is noteworthy that most of the inserts that are not in the written language are the names that make up the name.

TTA, forgotten in the written language of the historical and contemporary dialects used in the presence of attachments and the fact that many of these words derived from the derivation of the Turkish language is a great gain for research. The words with these suffixes will contribute to the solution of some problems in the history of Turkish language. At the same time, the addition of these attachments, which are not written in the written language, adding the appropriate words from these words to the written language will add strength to the power of Turkish.

Key words: dialects of Turkish in Turkey, word formation, derivational suffixes. 